\title{
AN EXPERIMENTAL INVESTIGATION ON SOLID AND PERFORATED STEEL STORAGE RACKS UPRIGHTS
}

\author{
Baldassino Nadia (1), Bernuzzi Claudio (2), Di Gioia Arturo (3) and Simoncelli Marco (2)
(1) Department of Civil, Environmental and Mechanical Engineering, Università degli Studi di Trento, Trento-Italy.
(2) Department of Architecture, Built Environment and Construction Engineering, Politecnico di Milano, Milano-Italy. \\ (3) Metalsistem S.p.A., Rovereto, Trento-Italy.
}

\begin{abstract}
Thin-walled cold-formed (TWCF) profiles are extensively used in adjustable selective pallet racks that represent the most common typology between the logistic solutions. In these structures, vertical members (uprights) are usually channels, often provided with intermediate stiffeners, rear flanges and additional lips. Furthermore, in order to allow for a rapid connection with beams and bracing components, usually uprights present regular perforation systems along their length. Nowadays, theoretical approaches available to design TWCF members are based on equations valid only for few unperforated (solid) cross-section geometries. As a consequence, rack manufacturing engineers frequently adopt the well-known design-assisted-by-testing approach to overcome this limitation and to assess accurately member performance. This approach, time consuming and cost demanding, stresses the need of further improvements required to cover aspects currently not considered in design codes.

The paper summarizes the results of a study focused on the response of a commercial upright profile. In particular, 48 compression and 24 bending tests on perforated and unperforated profiles have been carried out. A summary of the experimental program is proposed together with the reelaboration of test data. Furthermore, the influence of perforation is discussed as well as key design geometric parameters. Finally, owing to the lack of information in major rack standard codes, three different proposals to evaluate the effective second moments of area have been developed, discussed and applied, hoping to contribute to standard improvements.
\end{abstract}

Keywords: thin-walled cold-formed (TWCF) members, solid and perforated members, stub-column tests, bending tests, effective geometric properties.

\section{INTRODUCTION}

Nowadays, the use of thin-walled cold-formed (TWCF) steel members is spreading worldwide in several application fields, from low-rise residential buildings to industrial solutions in logistic for the storage of goods and products (racks) [1-3], that are the core of the present paper. Rack convenience, mainly due to the cheap manufacturing process allowing for high standardization level, lightness and rapidity of construction, is however counter-balanced by very complex design rules. The behaviour of the key components is in fact strongly influenced by buckling phenomena, i.e. local, distortional and global buckling as well as by their mutual interactions [4-7] that require to be suitably accounted for complex and tedious analytical evaluations. Furthermore, these approaches cannot be applied in case of perforated members, frequently used as vertical components (uprights) in racks.

In this paper, the attention is focused on the performance of the uprights. Figure 1 shows examples of typical upright cross-section geometries, which, as can be observed, are usually channels generally provided by multiple stiffeners, rear flanges and additional lips. Moreover, a regular system of perforations is distributed along the total length of the member, which can be located on both the web and the lips. The former perforation system allows for a speed-lock connection between the upright and the beams in the down-aisle direction (Figure 2a), while the latter is used to connect the lips of 
the uprights to the bracing components in the cross-aisle direction (Figure 2b). Perforations are also frequently used for the connection of the base-plate details to the upright (Figure 2c).

From the designer point of view, according to European standard [8], the performance of unperforated (solid) cross-section members can be theoretically assessed for a quite limited number of crosssection types, satisfying specific limits in terms of width-to-thickness ratios. In these cases, the wellestablished effective width approach [9] is efficiently adopted to account for the effects of local and distortional buckling, but the presence of perforations is not considered. On the other hand, the US TWCF provisions [10] offer a more general approach, that is the so-called Direct Strength Method (DSM), calibrated by researches over the years against experimental results on a quite wide variety of solid cross-section shapes [11,12], including rack sections [13], that are not yet covered by these provisions.

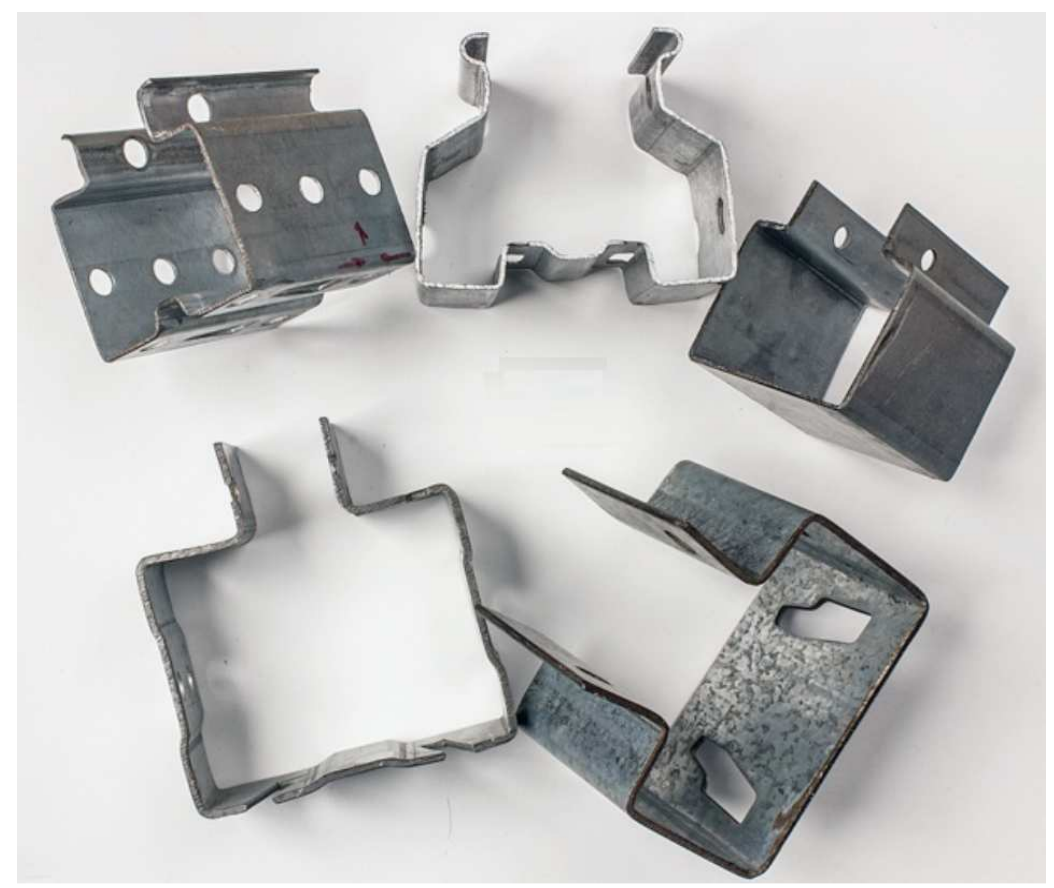

Figure 1. Profiles used as uprights for steel storage rack systems.

The influence of perforations has been quite deeply investigated in recent years. Various studies analyzed, both numerically and experimentally, the effect of simplified geometries of perforations on the response of plain and lipped channels [14-16]. As an example, studies by Baldassino and Hancok [17], Casafont et al. [18] and Moen [19] focused on the response of commercial rack uprights with different geometries. The comparison of the response of unperforated and perforated profiles of different length allowed for pointing out the influence of perforations on both the load carrying capacity and the collapse mode.

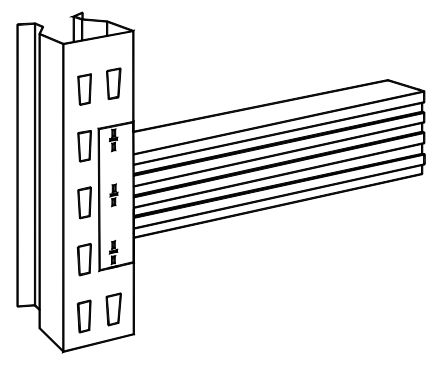

a)

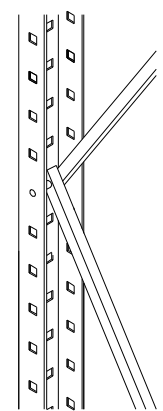

b)

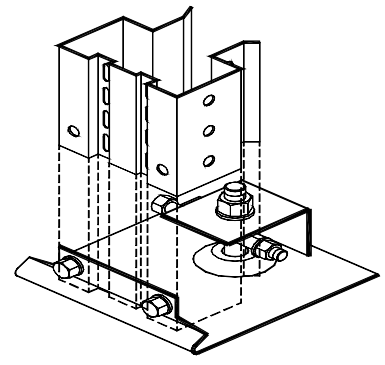

c)

Figure 2. Details of connections in steel storage rack systems: a) beam-to-column, b) bracing components and c) base-plate. 
The level of reliability of DSM in case of regular perforation systems was also investigated by considering the behavior of perforated and non-perforated uprights under axial compression [20,21]. The comparison of the collapse load and failure modes pointed out a low level of reliability of DSM if applied to predict ultimate load.

Despite the considerable improvements of the research on racks, in case of perforated members, the design assisted-by-testing approach [22] seems, until now, the most reliable way for practical design purposes. In order to decrease the non-negligible costs associated with the experimental activities, i.e. the costs of the testing setup, the live-cost associated with specimens, the costs of the laboratory staff, and the time required to elaborate the test data, a mixed approach which combines few tests and several finite element (FE) analyses could be really convenient. In this direction, research efforts have been addressed in some papers published in recent years [23-26]. Furthermore, refined FE models have been extensively used for the study of all the rack components, especially uprights, beam-tocolumn or base plate connections [27,28], characterized by a marked non-linear response, normally appraised via expensive experimental activities. Finally, it is worth noting that finite element models have been used also in studies of the behavior of full-scale rack frames [29-33] pointing out the need of refined beam formulations or very expensive models using shell elements in order to capture the complex experimental response.

This paper presents the results of a research on the influence of perforations on the response of a commercial rack profile. The study focused on the parameters influencing directly the load carrying capacity, i.e. the effective area, the bending resistance and the second moments of area of the profile. At this aim, the results of compression and bending tests on unperforated and perforated members are herein presented and discussed. The lack of practical indications offered by the European standards [34] about the procedure to experimentally evaluate the second moments of area and the key role of this data for design purposes as stressed in the revised version of EN15512 [35] suggested a detailed study of this subject. The outcomes can be considered a starting point for future FE numerical studies simulating full scale-experimental tests [36,37] and should be useful, in the Authors' opinion, for an improvement of the rack provisions.

\section{THE EXPERIMENTAL PROGRAMME}

As previously mentioned, the study concerns a commercial cold-formed rack profile, presented in Figure 3. As can be observed, it is an open channel with rear flanges with additional lips and one web stiffener. It is also provided by a regular pattern of perforations located on the web, on the lips and on the rear flanges. Key details about the section geometry and the perforation layout associated with each module are presented in Table 1 and Figure 4, respectively. Owing to commercial confidentiality reasons, all geometric and performance data are presented in non-dimensional form, without however any reduction of the field of validity of the research outcomes. More in detail, in Table 1, the thickness, the ratio between the gross second moments of area along the principal directions $\left(I_{g, y} / I_{g, z}\right)$ and the ratio between the eccentricity of the shear center $\left(y_{s}\right)$ and the position of the centroid of the gross section $\left(y_{g}\right)$, with respect to the web, are reported. In the table is reported also the torsional slenderness, $\lambda_{t}$, that is defined as:

$$
\lambda_{t}=\sqrt{\frac{G I_{t}}{E I_{w}}}
$$

where $G$ and $E$ are the shear modulus and the Young's modulus, respectively, $I_{t}$ is the Saint Venant constant and $I_{w}$ is the warping constant.

Furthermore, the data related to the gross cross-section modulus $\left(W_{g}\right)$ along the principal $y$ and $z$ directions, are reported in the table too, and subscripts min and Max are related to the minimum and maximum section modulus, respectively for bending along the non-symmetry axis. 

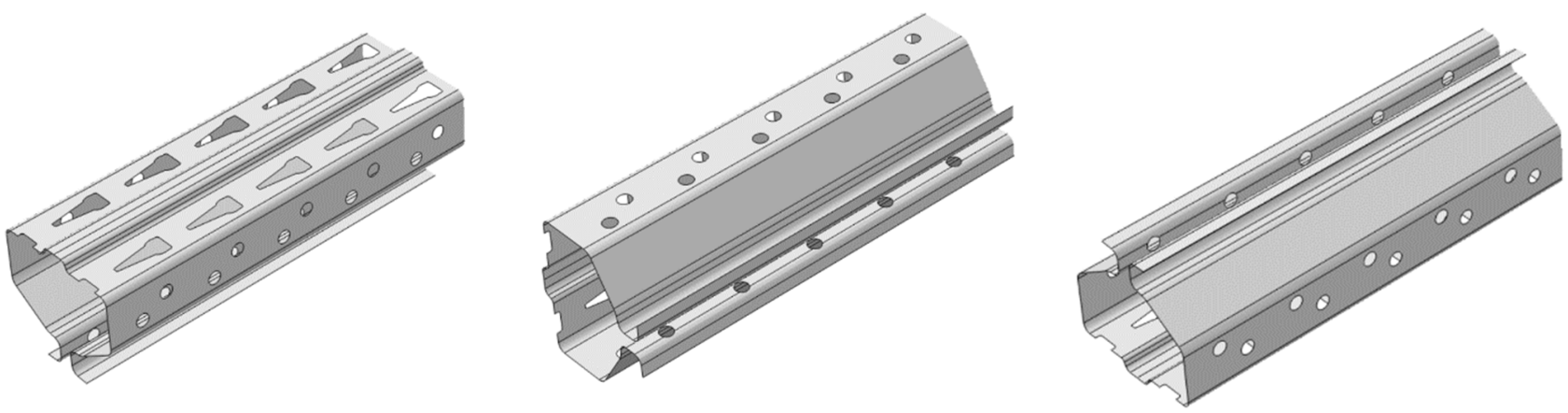

Figure 3. Different global 3-D views of the considered member.

Table 1. Cross-section dimensions and characteristics.

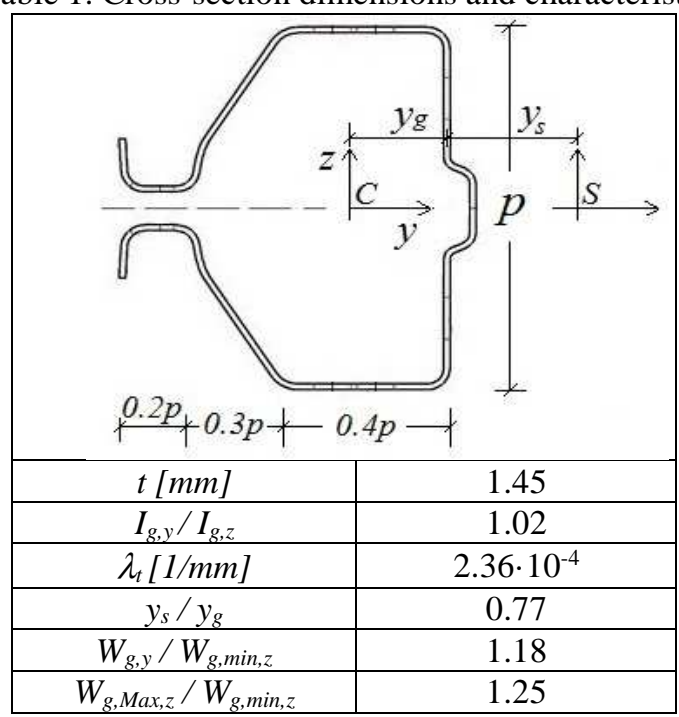

As to the perforation system, Figure 4 can be considered: four significant cross-sections ( $c s$ ) differing for the amount of perforated area (ratio between the perforated and unperforated (gross) area), can be clearly identified in the upright module:

- cs. 1, having holes in the web and in the flanges, and with a perforated area corresponding approximately to $15 \%$ of the one associated with the unperforated cross-section;

- cs. 2, the most perforated one, with holes in the web, flanges and stiffeners (approximately 25\% of the total area is loss due to perforations);

- cs. 3, with perforations only in the web (2\% of loss area);

- cs. 4, un-perforated cross-section.

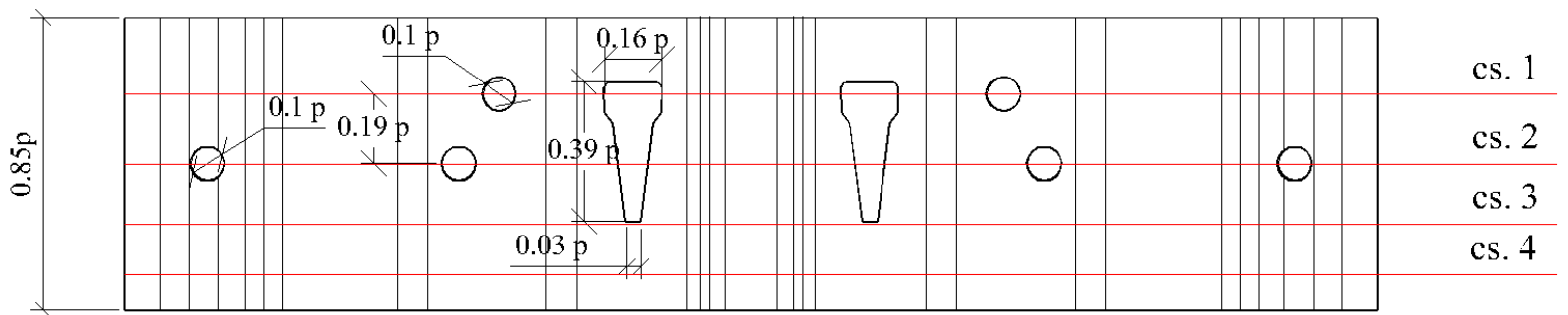

Figure 4. Non-dimensional geometry of the perforations associated with a module of length $0.85 \mathrm{p}$.

Nominally equal specimens, differing only for the presence or the absence of perforations along the length, have been tested under pure compression and under mono-axial bending. In the following, the specimens with holes are identified as H-type, while the ones without holes are named S-type. Both $\mathrm{H}-$ and S-types have been produced from the same steel coil. 
Due to the great influence of the material properties on the experimental results [38], five tensile tests have been performed to determine the material properties of the steel. The values of the yielding $\left(f_{y}\right)$, the ultimate strength $\left(f_{u}\right)$ and the Young modulus $(E)$ are reported in table 2, together with the mean value, the standard deviation and the coefficient of variation. In particular, flat coupons, flat coupons, with the typical backbone shape, have been extracted from the coil used to produce the specimens, before any cold-forming process (perforation, rolling, punching....). This allowed for evaluating the material properties of the 'virgin' steel without any influence of the cold-forming processes, which increase both the yielding and the ultimate stress in the corner zones and around the holes, as already well-established in the past [39]. Tests have been performed according to the EN ISO 6892-1 [40]. As to the yielding and ultimate strength it can be noted a quite moderate dispersion of the experimental results. The same remark regards also the Young's modulus but is worth noting that the effective value is significantly lower than the one prescribed by European provisions for storage racks as well as for the more traditional carpentry steel frames, i.e $210000 \mathrm{~N} / \mathrm{mm}^{2}$, (approximately $14 \%$ ).

Table 2. Properties of the virgin material

\begin{tabular}{|c|c|c|c|}
\hline Sample & $\begin{array}{c}f_{y} \\
{\left[\mathrm{~N} / \mathrm{mm}^{2}\right]}\end{array}$ & $\begin{array}{c}f_{u} \\
{\left[\mathrm{~N} / \mathrm{mm}^{2}\right]}\end{array}$ & $\begin{array}{c}E \\
{\left[\mathrm{~N} / \mathrm{mm}^{2}\right]}\end{array}$ \\
\hline 1 & 420.1 & 463.8 & 177710 \\
\hline 2 & 420.5 & 467.4 & 189050 \\
\hline 3 & 418.3 & 459.2 & 175770 \\
\hline 4 & 418.1 & 464.9 & 179840 \\
\hline 5 & 421.2 & 461.9 & 180120 \\
\hline $\begin{array}{c}\text { Standard } \\
\text { deviation }\end{array}$ & 1.374 & 3.094 & $\begin{array}{c}180498 \\
(\approx 180500)\end{array}$ \\
\hline CoV\% & 0.33 & 0.67 & 2.82 \\
\hline
\end{tabular}

\subsection{Elastic buckling analysis}

Preliminary elastic buckling analyses for the unperforated profile were performed by using the CUFSM software [41] and the member response was appraised under pure axial force and pure bending moments. The cross-section was modelled via 47 nodal points, for a total of 46 elements and each round corner has been simulated as piecewise linear via 3 elements. Both for compression and bending, a stress distribution characterized by the achievement of the mean value of the yielding of the material $\left(420 \mathrm{~N} / \mathrm{mm}^{2}\right)$ has been considered and results are presented with respect to the stress distribution multiplier, simply indicated in the following as "load factor", plotted versus the effective length. Also, the modal participation factor of principal buckling modes in each selected length are reported, obtained by using the vector norm classification available in the software. As to the pure compression case, results of the analysis are summarised in Figure 5. It can be noted that in the selected range of lengths, the dominant elastic buckling mode is always the distortional one, i.e. percentage of participation ranging from $96 \%$ to $82 \%$. Furthermore, the influence of local buckling in all cases is extremely limited (lower than $2 \%$ ) while for the greatest length the influence of global (flexural) buckling is less than $20 \%$. 


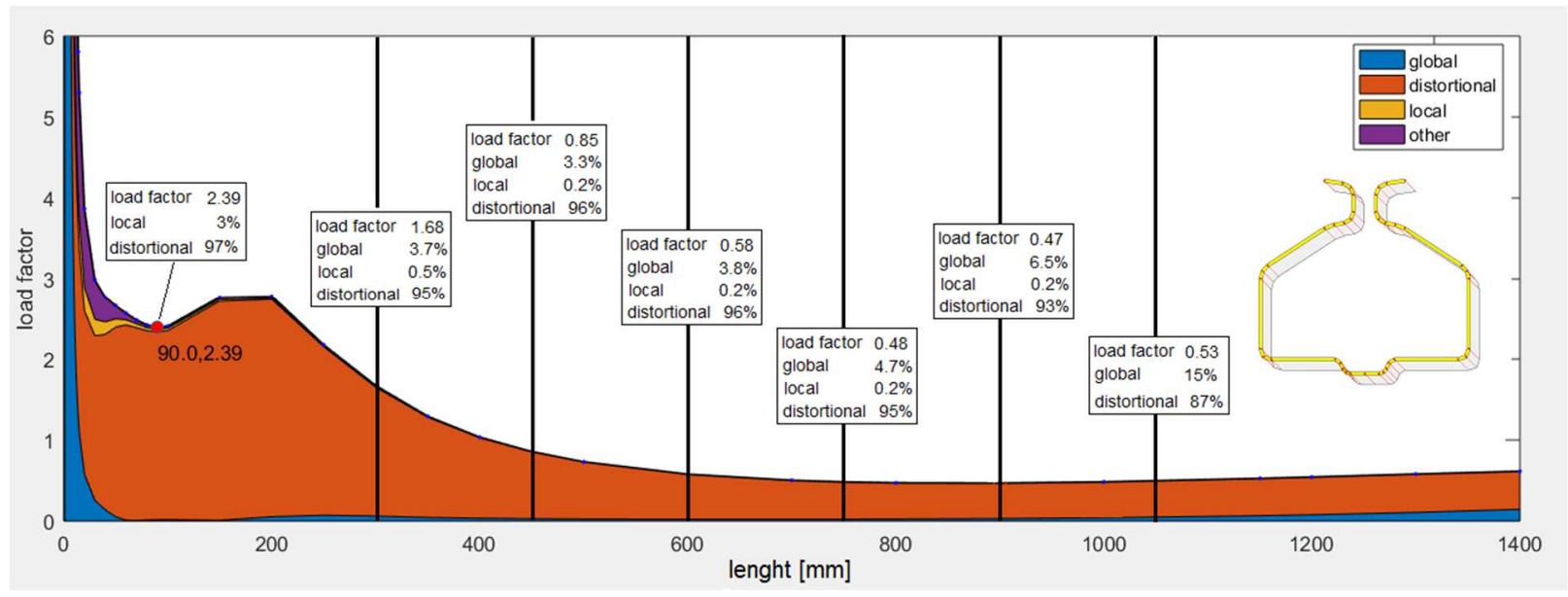

Figure 5. Stability curves for S-type profile under compression, obtained from CUFSM [41].

As to the response to bending moments, owing to the presence of a single axis of symmetry, attention has been focussed on three different stress distributions: one for investigating the behaviour on the down-aisle direction (bending along the y-axis, according to table 1) and the others for the behaviour along cross-aisle directions ( $\mathrm{z}$-axis).

As to the former, reference can be made to Figure 6. It can be noted that the influence of distortional buckling is never negligible, decreasing with the increase of the member effective length, dominating on the global one up to $1.5 \mathrm{~m}$, approximately. Furthermore, the percentage of the local buckling mode for the length values of interest is always the lowest.

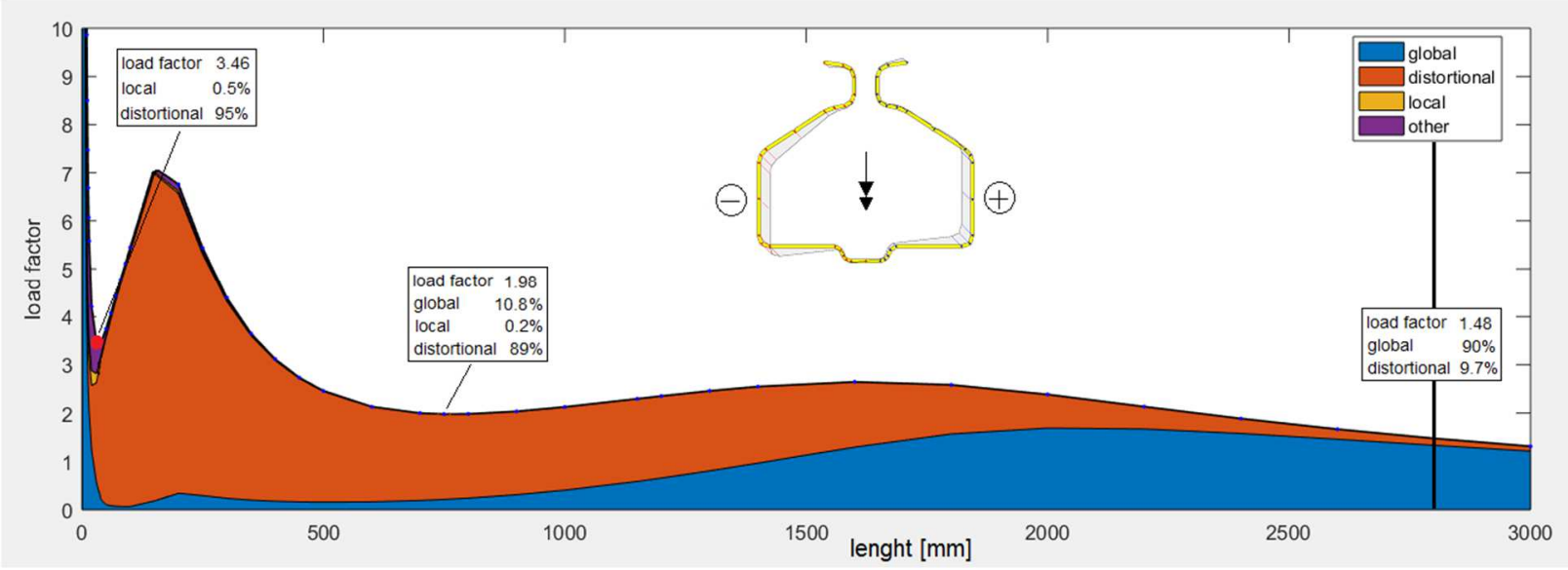

Figure 6. Stability curves for S-type profile under bending along y-axis, obtained from CUFSM [41].

As to the flexural behaviour along the non-symmetric direction, two types of stress distributions have been considered, differing for the parts of the cross-section in tension (or compression). To identify them, avoiding misunderstanding, reference is made to the state of stress on the rear ends. Negative (neg) and positive (pos) bending distribution, whose response is presented in figures 7 and 8 , respectively, are conventionally related to tests inducing compression or tension, respectively in this zone. It can be noted that for negative bending distortional buckling modes are predominant on the global up to $1.5 \mathrm{~m}$, being practically negligible the influence of the other modes. For effective lengths greater than $1.8 \mathrm{~m}$, approximately, the flexural buckling mode becomes the dominant one. Otherwise, in case of positive bending, the contribution of the distortional buckling mode, initially approximately greater than $90 \%$ decreases smoothly with the increment of the global one, and, for the highest value of the effective length, unlike the previous bending cases, it is quite limited but however nonnegligible for practical design purposes. 


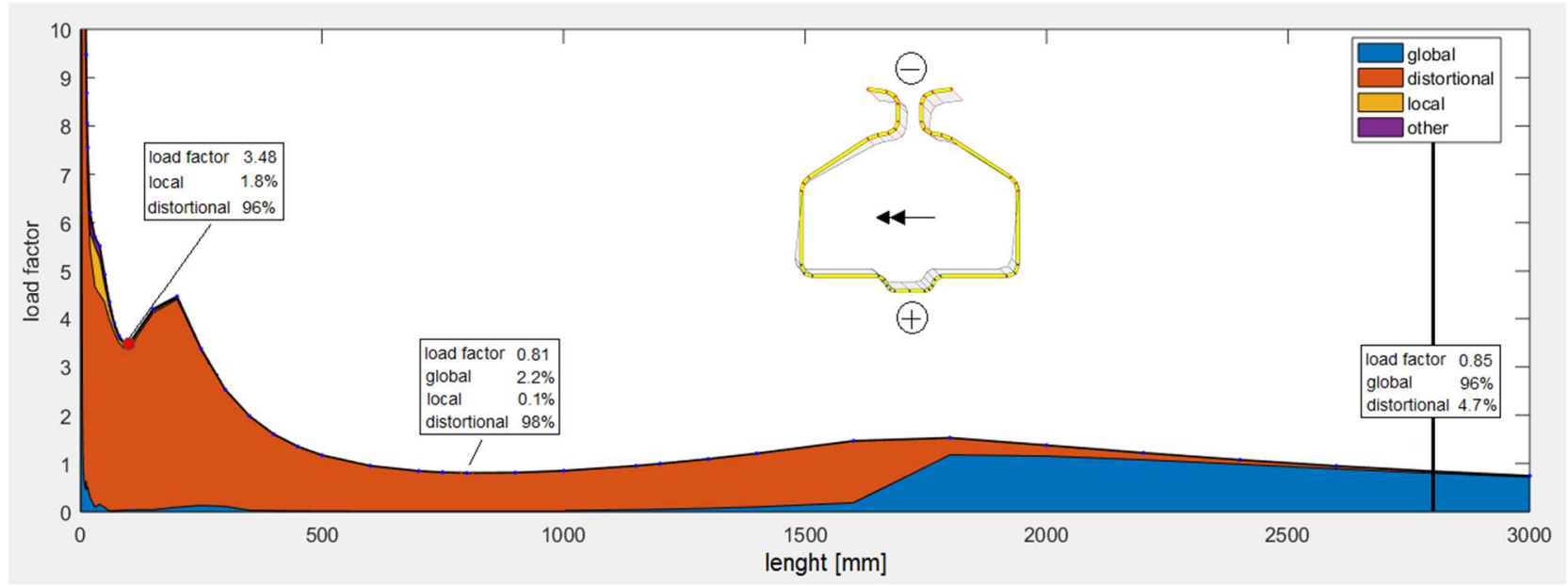

1

Figure 7. Stability curves for S-type profile under z-negative bending, obtained from CUFSM [41].

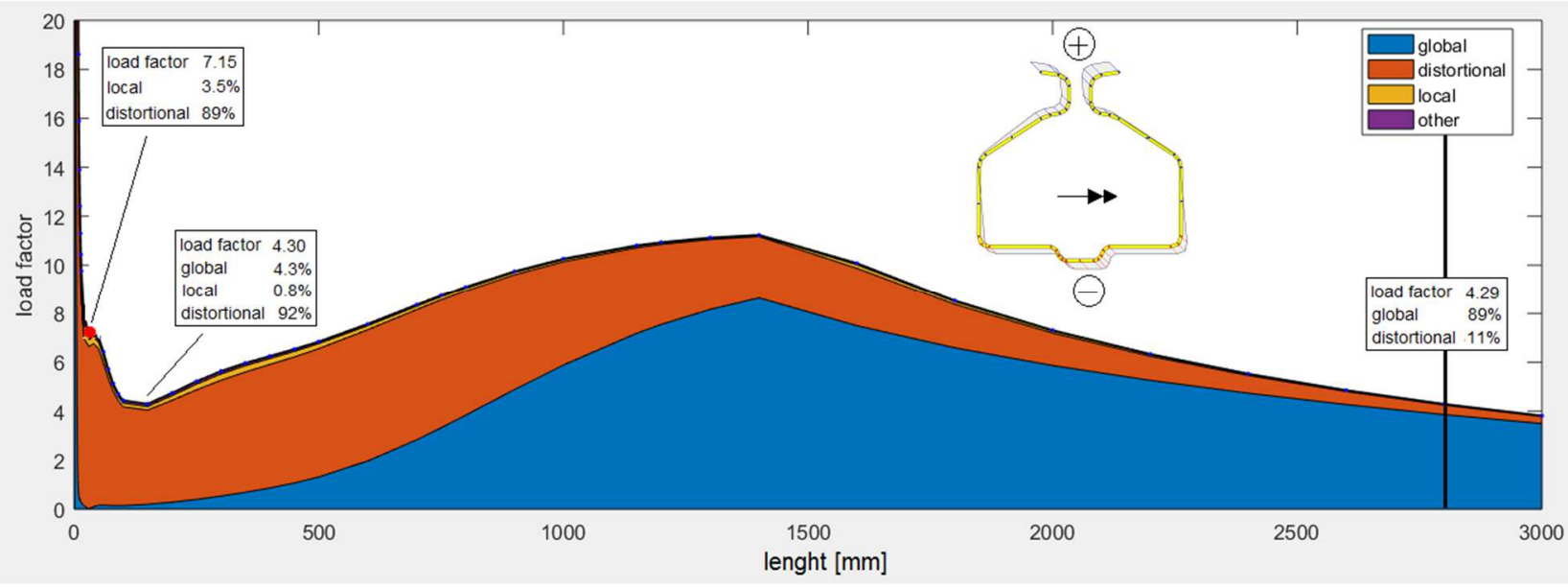

Figure 8. Stability curves for S-type profiles under z-positive bending, obtained from CUFSM [41]. 


\subsection{Compression tests}

Compression tests have been performed according to EN15512 [34] on specimens of different length $(300,450,600,750,900,1150 \mathrm{~mm})$ in order to investigate the local and distortional failure modes and their mutual interaction (Figure 9). All the tests have been executed under load control. The range of the considered lengths has been defined in order to appraise the different buckling modes, influenced by local and/or distortional modes, and the height of the specimen has been defined by the need of having an un-perforated cross-section in correspondence of the thick plate as well as by the pitch of the perforation modulus.

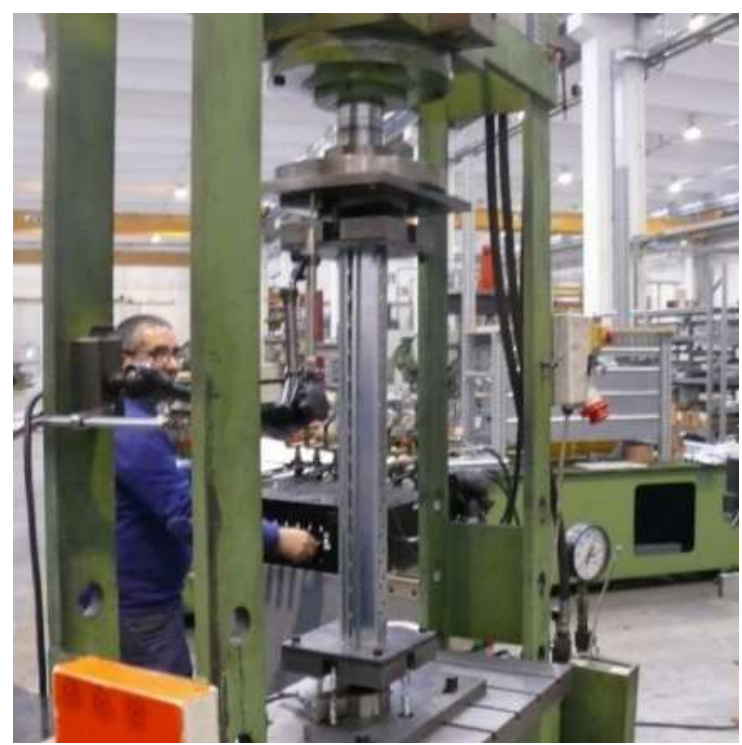

Figure 9. Compression test set-up.

The specimen lengths have been selected as in the following specified:

- the shortest one (i.e. $300 \mathrm{~mm}$ ), selected to investigate the influence of local buckling, satisfies the requirements of EN 15512 [34], i.e. length value satisfies both the requisites of being 3.5 times the width of the specimen and of including at least five pitches of perforations;

- the longest one (i.e. $1150 \mathrm{~mm}$ ) corresponds to the distance of two subsequent nodes of the bracing system in the transversal (cross-aisle) direction of the most commonly used upright frame configuration;

- the other lengths, intermediate from the shortest to the longest, were chosen by maintaining a constant step of $150 \mathrm{~mm}$.

For each selected length value, four compression tests were performed on nominally equal specimens. Like for the more traditional hot-rolled carpentry components, imperfections can be found as out-ofstraightness of the member or as a distortion of the cross-section. An efficient set-up for the imperfection measurements has been proposed in literature [42] but, due to its complexity, it has not been used in the present research, as it happens for the commercial manufacturing tests. It is worth noting that initial geometric imperfections play a non-negligible role on the effective member performance when numerical finite element models are adopted. Owing to the aims of the present papers, only experimental results are herein considered and, as a consequence, the presence of imperfections is directly accounted for from test data.

The EN15512 recommendations [34], in order to facilitate the interface with the testing apparatus, prescribe that specimens for compression tests are prepared by welding a thin plate at both ends of the specimen. To reduce the costs of the tests and at the same time improving their repeatability, an alternative specimen layout was adopted in this research. The portion of the upright of appropriate length was placed directly between two thick plates (having a thickness of $12 \mathrm{~mm}$ ) work-machined with furrows ( $8 \mathrm{~mm}$ depth) reproducing the cross-section of the specimen (Figure 8), avoiding, as a consequence, any type of slip and slack as well as secondary eccentricities due to the effective 
position of the fillet welds. The thick plates were connected to a hydraulic jack and to a loading cell (maximum capacity of $220 \mathrm{kN}$ ) via spherical hinges. The effectiveness of the ends restraint system was verified by comparing the results of tests carried out adopting the two different end finishing systems (i.e. pre-shaped plates and welded plates).

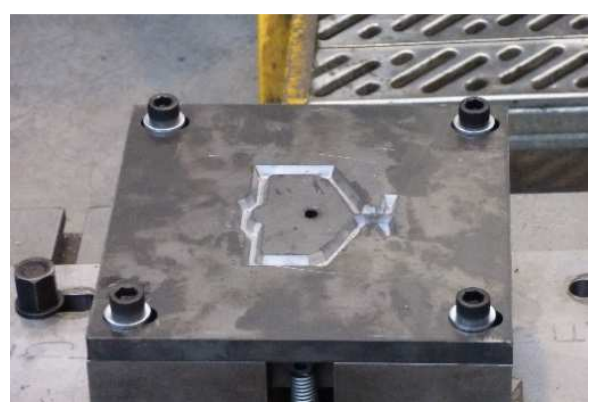

a)

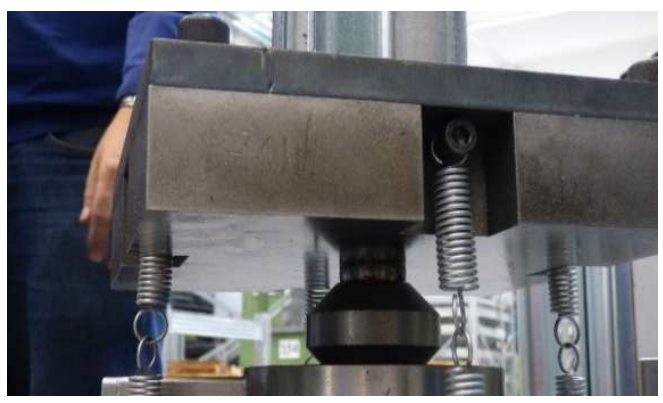

b)

Figure 10. Details of compression test: a) the end restrains and b) the spherical hinge.

As concern to the applied load, it should be remarked that, while for S-type specimens the position of the section centroid can be theoretically evaluated, in case of H-type specimens the presence of cross-sections with different characteristics along the member length (Figure 4) prevents this evaluation. Therefore, the load was always applied in correspondence of the centroid of the gross section, independently on the presence/absence of perforations. During the tests, the applied load and the vertical displacement of the specimen $\delta$ (i.e. the shortening of the specimen) were recorded via a data logging system at a frequency of $2 \mathrm{~Hz}$. Test results were evaluated in terms of experimental ultimate load $\left(P_{u, i}\right)$, mean value of the ultimate load of specimens of the same length $\left(P_{u, m}\right)$ and associated standard deviation (st.dev.). Attention was also paid to the characteristic value of the ultimate load $\left(P_{u, k}\right)$, i.e. to the value to be considered for design purposes according to limit state design philosophy, that is based on statistical analysis of the test results of four nominally equal specimens, according to criterion addressed in the European rack code. All these quantities, divided by the squash load of the gross cross-section $\left(P_{y}=A_{g} \cdot f_{y}\right)$, are reported in Table 3 together with the observed failure modes. It is worth noting that the ratio between the effective and the gross crosssection area is the well-known $Q$ reduction factor. It is worth mentioning that the classification of perforated cross-section is not addressed in the Eurocode 3 part 1-1 [43] and it has been decided to use the gross cross-sectional area, $A_{g}$, as reference term to present test results in non-dimensional form.

Table 3. Summary of the stub-column test results.

\begin{tabular}{|c|c|c|c|c|c|c|c|c|c|c|c|}
\hline \multicolumn{2}{|c|}{ Specimen } & \multicolumn{5}{|c|}{ S-type } & \multicolumn{5}{|c|}{ H-type } \\
\hline Length & ID & $\frac{P_{u, i}}{P_{y}}$ & $\frac{P_{u, m}}{P_{y}}$ & st.dev. & $\frac{P_{u, k}}{P_{y}}$ & $\begin{array}{l}\text { failure } \\
\text { mode }\end{array}$ & $\frac{P_{u, i}}{P_{y}}$ & $\frac{P_{u, m}}{P_{y}}$ & st.dev. & $\frac{P_{u, k}}{P_{y}}$ & $\begin{array}{l}\text { failure } \\
\text { mode }\end{array}$ \\
\hline \multirow{4}{*}{$\begin{array}{l}300 \\
\mathrm{~mm}\end{array}$} & 1 & 0.913 & \multirow{4}{*}{0.91} & \multirow{4}{*}{0.0171} & \multirow{4}{*}{0.87} & $\mathrm{~L}$ & 0.750 & \multirow{4}{*}{0.74} & \multirow{4}{*}{0.0166} & \multirow{4}{*}{0.70} & $\mathrm{~L}$ \\
\hline & 2 & 0.898 & & & & $\mathrm{~L}$ & 0.741 & & & & $\mathrm{~L}$ \\
\hline & 3 & 0.890 & & & & $\mathrm{~L}$ & 0.717 & & & & $\mathrm{~L}$ \\
\hline & 4 & 0.929 & & & & $\mathrm{~L}$ & 0.753 & & & & $\mathrm{~L}$ \\
\hline \multirow{4}{*}{$\begin{array}{l}450 \\
\mathrm{~mm}\end{array}$} & 1 & 0.811 & \multirow{4}{*}{0.79} & \multirow{4}{*}{0.0147} & \multirow{4}{*}{0.75} & $\mathrm{~L}$ & 0.718 & \multirow{4}{*}{0.72} & \multirow{4}{*}{0.0122} & \multirow{4}{*}{0.69} & $\mathrm{~L}+\mathrm{D}$ \\
\hline & 2 & 0.795 & & & & $\mathrm{~L}$ & 0.706 & & & & $\mathrm{~L}+\mathrm{D}$ \\
\hline & 3 & 0.775 & & & & $L+D$ & 0.735 & & & & $\mathrm{~L}+\mathrm{D}$ \\
\hline & 4 & 0.792 & & & & $\mathrm{~L}+\mathrm{D}$ & 0.723 & & & & $\mathrm{~L}+\mathrm{D}$ \\
\hline \multirow{4}{*}{$\begin{array}{l}600 \\
\mathrm{~mm}\end{array}$} & 1 & 0.737 & \multirow{4}{*}{0.72} & \multirow{4}{*}{0.0134} & \multirow{4}{*}{0.69} & $\mathrm{D}$ & 0.679 & \multirow{4}{*}{0.68} & \multirow{4}{*}{0.0102} & \multirow{4}{*}{0.66} & $\mathrm{D}$ \\
\hline & 2 & 0.723 & & & & $\mathrm{D}$ & 0.699 & & & & $\mathrm{D}$ \\
\hline & 3 & 0.704 & & & & $\mathrm{D}$ & 0.682 & & & & $\mathrm{D}$ \\
\hline & 4 & 0.720 & & & & $\mathrm{D}$ & 0.676 & & & & $\mathrm{D}$ \\
\hline \multirow[b]{2}{*}{750} & 1 & 0.667 & \multirow{2}{*}{0.67} & \multirow{2}{*}{0.0117} & \multirow{2}{*}{0.64} & $\mathrm{D}$ & 0.579 & \multirow{2}{*}{0.61} & \multirow{2}{*}{0.0188} & \multirow{2}{*}{0.55} & $\mathrm{D}$ \\
\hline & 2 & 0.673 & & & & $\mathrm{D}$ & 0.607 & & & & $\mathrm{D}$ \\
\hline
\end{tabular}




\begin{tabular}{|c|c|c|c|c|c|c|c|c|c|c|c|}
\hline \multirow[t]{2}{*}{$\mathrm{mm}$} & 3 & 0.661 & & & & $\mathrm{D}$ & 0.617 & & & & $\mathrm{D}$ \\
\hline & 4 & 0.688 & & & & $\mathrm{D}$ & 0.635 & & & & $\mathrm{D}$ \\
\hline \multirow{4}{*}{$\begin{array}{l}900 \\
\mathrm{~mm}\end{array}$} & 1 & 0.644 & \multirow{4}{*}{0.65} & \multirow{4}{*}{0.0178} & \multirow{4}{*}{0.60} & $\mathrm{D}$ & 0.552 & \multirow{4}{*}{0.57} & \multirow{4}{*}{0.0189} & \multirow{4}{*}{0.52} & $\mathrm{D}$ \\
\hline & 2 & 0.635 & & & & D & 0.581 & & & & $\mathrm{D}$ \\
\hline & 3 & 0.638 & & & & $\mathrm{D}$ & 0.562 & & & & D \\
\hline & 4 & 0.674 & & & & $\mathrm{D}$ & 0.594 & & & & $\mathrm{D}$ \\
\hline \multirow{4}{*}{$\begin{array}{c}1150 \\
\mathrm{~mm}\end{array}$} & 1 & 0.629 & \multirow{4}{*}{0.62} & \multirow{4}{*}{0.0183} & \multirow{4}{*}{0.57} & $\mathrm{G}+\mathrm{D}$ & 0.516 & \multirow{4}{*}{0.51} & \multirow{4}{*}{0.0101} & \multirow{4}{*}{0.49} & $\mathrm{G}+\mathrm{D}$ \\
\hline & 2 & 0.589 & & & & $\mathrm{D}$ & 0.526 & & & & $G+D$ \\
\hline & 3 & 0.626 & & & & $\mathrm{G}+\mathrm{D}$ & 0.505 & & & & $\mathrm{D}$ \\
\hline & 4 & 0.620 & & & & $G+D$ & 0.505 & & & & $G+D$ \\
\hline
\end{tabular}

failure modes: $L=$ local mode; $D=$ distortional mode; $G=$ global mode.

The results are also sketched in a more direct (graphical) form in Figure 11. In the figure, the isolated bullets identify the experimental results while the multi-linear lines are related to the mean (black curve) or the characteristic (red curve) values, respectively. Moreover, dashed curve refers to the Htype specimens while the solid curve to the S-type profiles.

As it appears from the figure and the table, for smaller lengths (300 and $450 \mathrm{~mm}$ ) a predominant local failure mode (L) was observed, while for the other lengths, the collapse was always due to distortional buckling (D), with the exception of the longest specimens (i.e. $1150 \mathrm{~mm}$ of length) interested by a mix between distortional (D) and global $(\mathrm{G})$ buckling mode, that is mainly due to interaction between bending and torsion. As expected, the observed failure modes are quite different from the pure elastic ones (Figure 5) due to the effective constitutive material law and to the presence of mechanical imperfections associated with the manufacturing processes. It is worth noting that the testing equipment allows for pure compression tests on unperforated members. In case of perforations a small value of eccentricity was due to the presence of cross-section differing for the perforation systems (Figure 4). However, the real member eccentricity is too limited for affecting remarkably to the actual load carrying capacity.

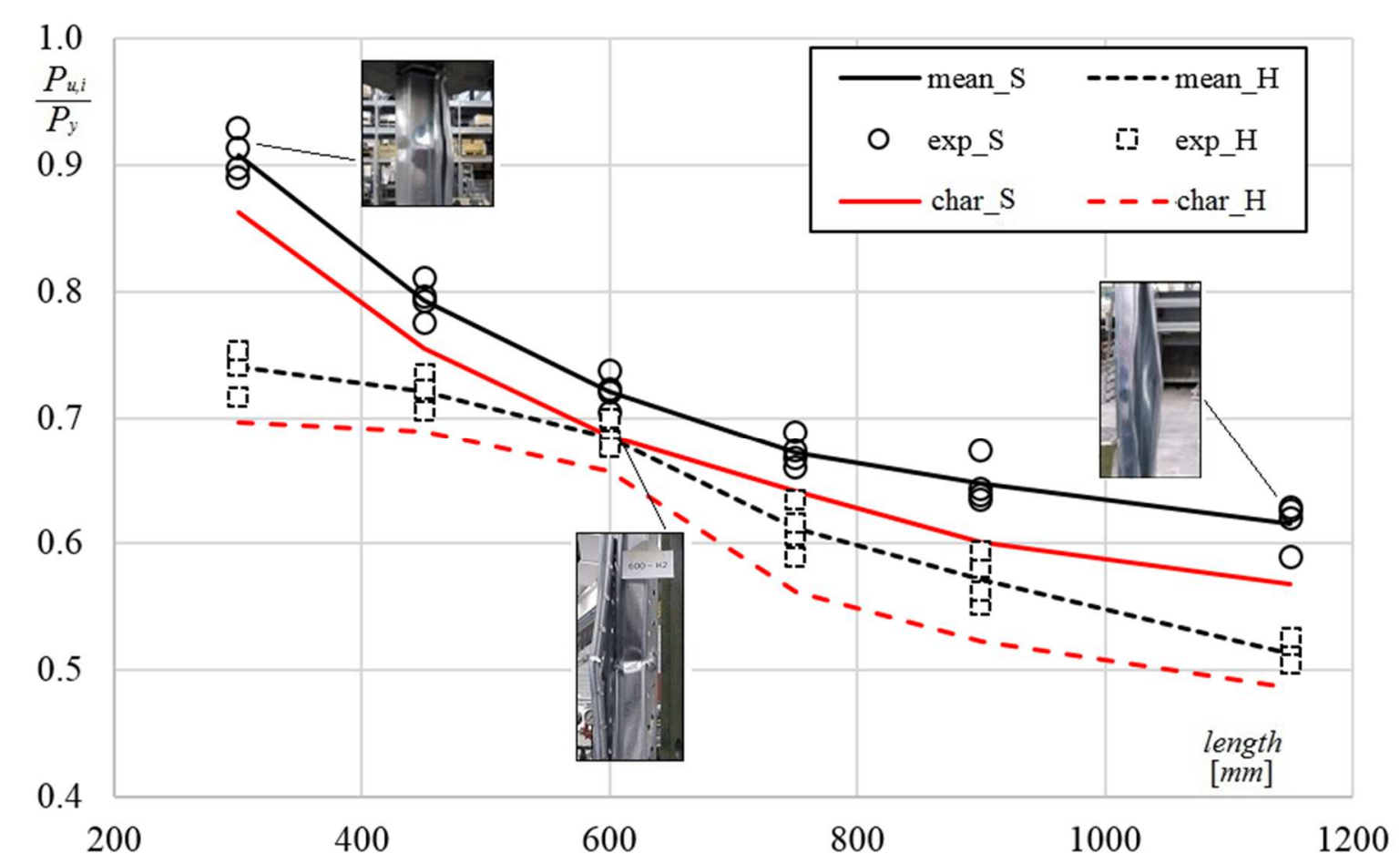

Figure 11. Mean and characteristic values of the load carrying capacity of the tested specimen vs. total length.

Results show a negligible influence of the perforations on the collapse mode while, as expected, the collapse load of the H-type specimens is lower than the one of the S-type: on average $14 \%$. The 
difference increases up to $24 \%$ and $17 \%$ for the shortest and the longest specimens, respectively, which corresponds approximately to the percentage of loss area in the cs. 2 and cs. 1 showed in Figure 4. The minimum difference (4\%) is associated with the length of $600 \mathrm{~mm}$. The differences between the characteristic and the mean value of the collapse load are on average of $6 \%$, with a maximum of $11 \%$ for H-type profiles with $750 \mathrm{~mm}$ of length. Moreover, it is worth noting that the maximum distortional displacements are never in the middle height of the specimen and the deformed amplitude is quite independent on the presence/absence of perforations. As it appears from Figure 12, this zone changes from test to test, also on members with same length, influenced principally by the geometric imperfections.
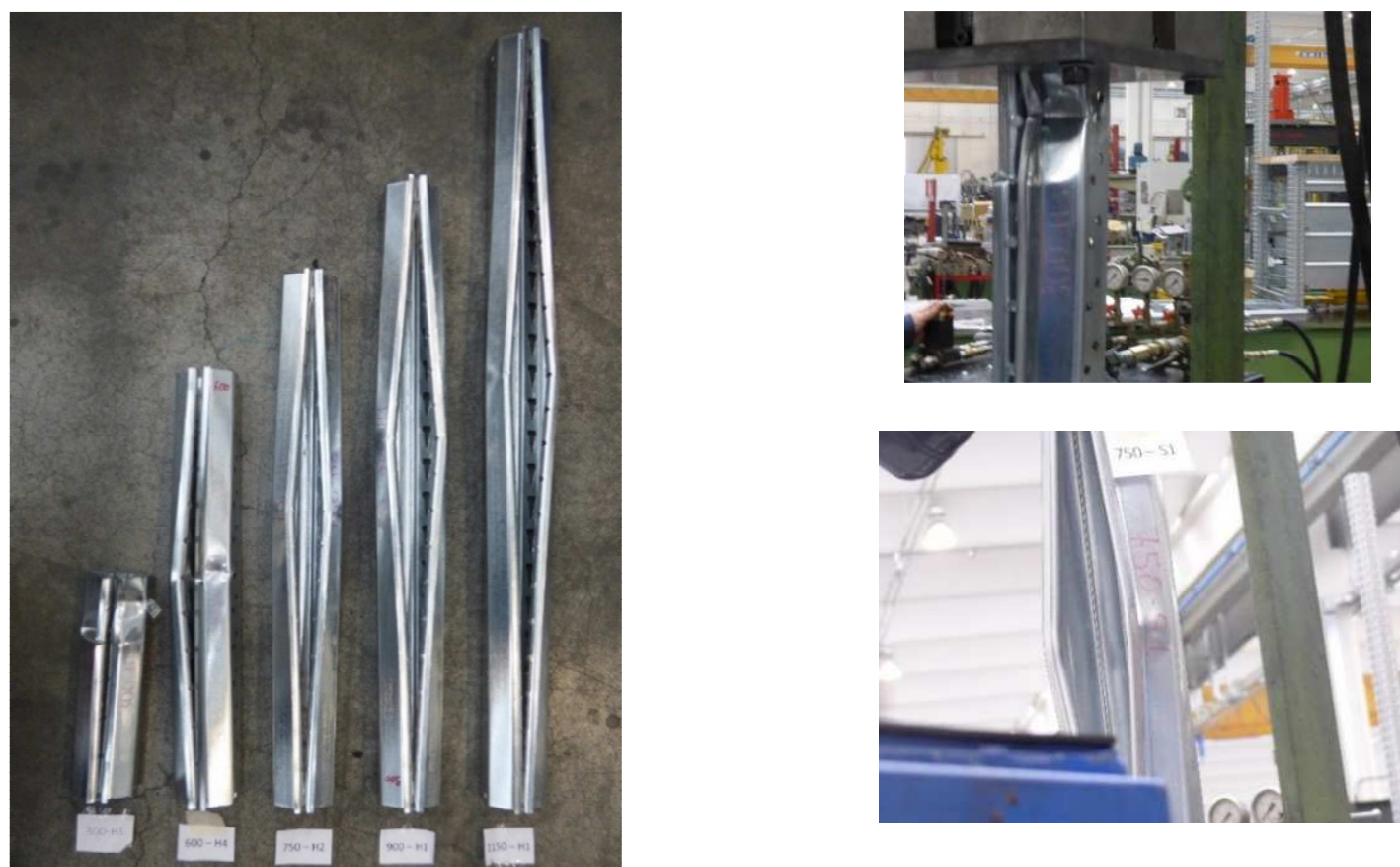

Figure 12. Different collapse modes for the profiles with different length.

Finally, it should be observed the limited dispersion of the experimental data, having a standard deviation never greater than $2 \%$, to confirm the efficiency of the adopted experimental equipment, allowing for tests with a high level of repeatability.

\subsection{Bending moment tests}

The flexural performance of the profile was experimentally investigated by means of the traditional four points bending test, which allows for a constant moment distribution between the applied loads, without any shear influence, and that is traditionally recommended as static scheme for investigating the bending behaviour also with reference to components made by different materials like wood, concrete, etc.... Due to the mono-symmetric geometry of the cross-section, bending tests were performed in both principal directions (i.e. $y$ - and z-axis according to Table 1). Tests were inspired by section A.2.9 of the EN15512 standard [34], which however requires improvements due to the limited indications concerning the details on the restraining system and on the efficient way to transfer the load to the specimen. It is worth noting that these aspects influence in a non-negligible way the specimen performance, as already discussed also in [43]. For these reasons, an 'ad hoc' set-up has been designed and used. Like for compression, four nominally equal specimens have been tested for each type of bending tests. In all tests, the total length of the specimens was $3000 \mathrm{~mm}$ while the distance between the end supports was $2800 \mathrm{~mm}$. As it appears from the elastic buckling analyses (see section 2.1) this value falls in the range in which the lateral buckling is dominant with respect to the distortional and local ones (Figures 6-8). Furthermore, the ratio between the end support distance 
and the cross-section width was 32 in perfect agreement with EN 15512 requirements, prescribing this ratio in the range $30 \div 40$. As to the measuring system, linear voltage displacement transduces (LVDTs) allowed for appraising the vertical displacements at the mid-span section and at the sections in correspondence to the applied loads (to evaluate the symmetric behaviour of the specimens). In the central section, in order to capture eventual torsional effects, the vertical displacement was recorded on the two opposite sides of the specimen. During tests, the applied load and the vertical displacements were automatically measured at a frequency of $2 \mathrm{~Hz}$.

\subsubsection{Bending tests in the down-aisle (y) direction}

Bending tests around the symmetric axis (around y-axis, according to Table 1) were carried out on specimens made by coupling two profiles front-to-front (Figure 13b), according to the general scheme proposed by the European provisions, which recommend the testing of a complete upright frame [34]. More in details, full-scale lacings have been avoided and reference has been made to a buttoned strut specimen, whose behaviour is however representative of the upright one. In order to avoid torsional effects, loads and restraints were realised so that the forces are directly applied to the shear centre (S) of the gross cross-section, as shown in Figure 13a. In the same figure the centroid of the section (C) is also indicated. The load is transferred from the hydraulic jack to the specimen by means of a stiff distribution beam made of two hot rolled lipped channels coupled on the flanges by means of batten plates. At each load application point, two spherical steel balls apply the force directly to the shear centre of the profiles (Figure 14a). A similar arrangement is adopted at the supports in order to recreate the ideal end restraint conditions of simply support and hinge. Both the unperforated (S-type) and perforated (H-type) profiles were examined and for each type, 4 nominally equal specimens were tested.

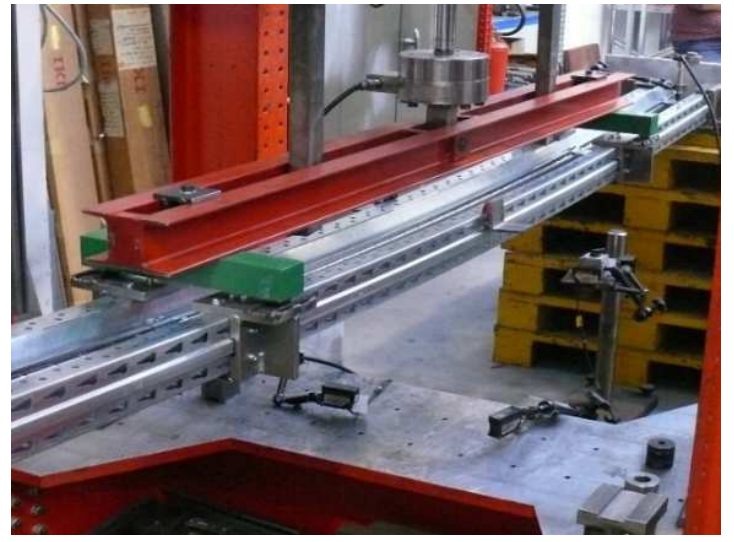

a)

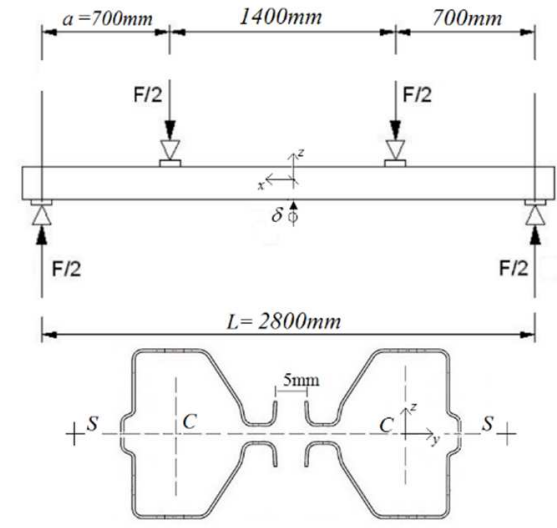

b)

Figure 13. Scheme of the bending test around the y-direction: a) global view of the testing set-up and b) the considered static scheme.

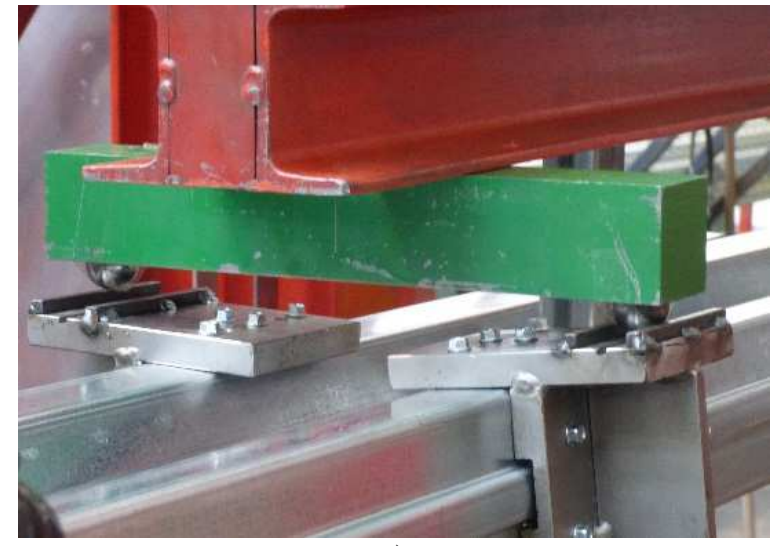

a)

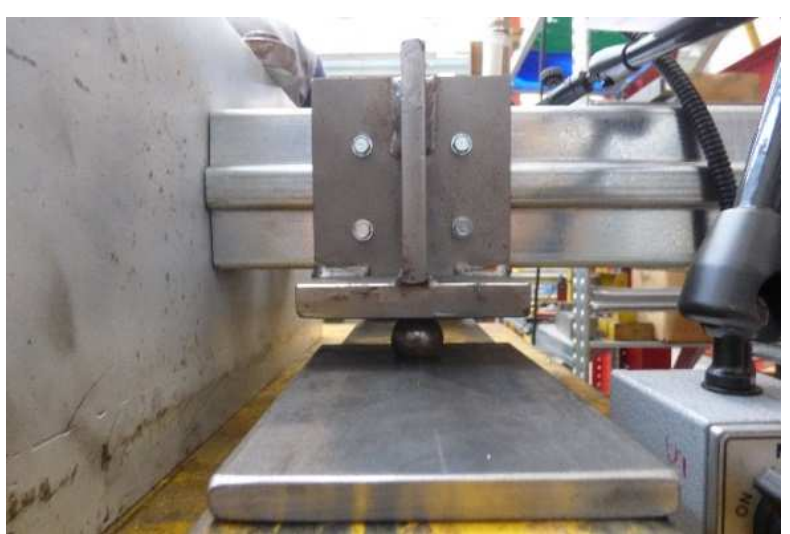

b)

Figure 14. Details of bending test: a) the load application point and b) the external restraint. 
In all the tests, the collapse was achieved in a section between the applied loads, i.e. in the zone under constant bending moment, as reported in Figure 15, very close to one of the load application points.

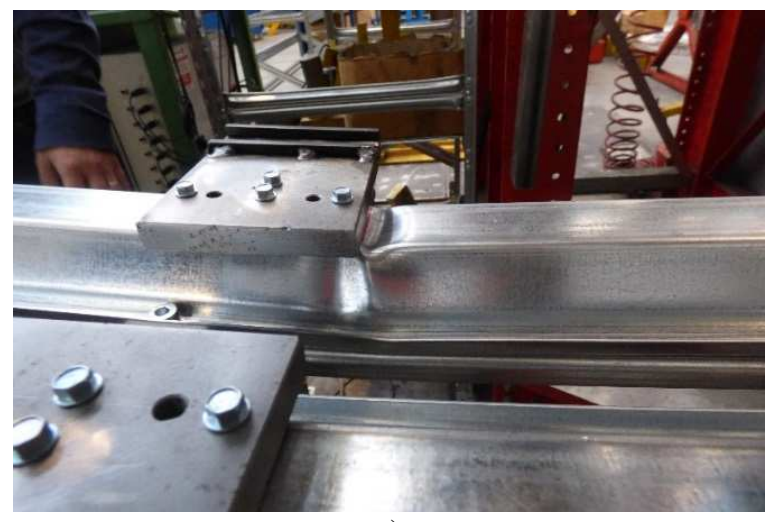

a)

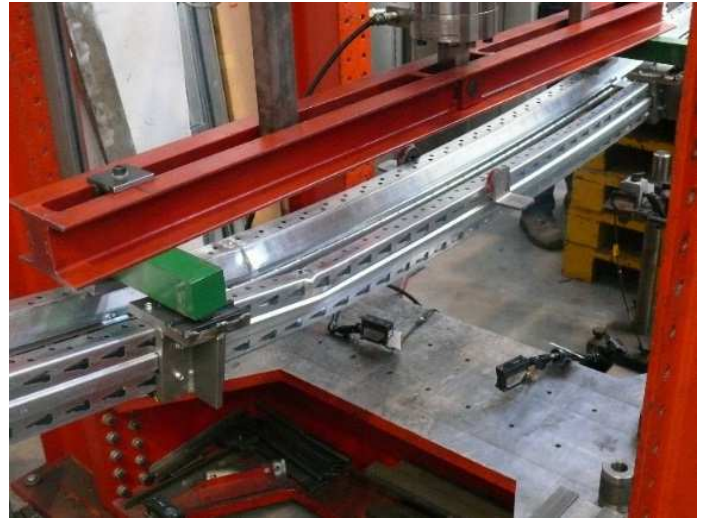

b)

Figure 15. Typical failure modes for a) the $\mathrm{S}$ - and b) the H-type specimens.

Figure 16 shows the non-dimensional load vs. mid-span section displacement curves: solid and dashed lines are related to S- and H-type profiles, respectively. In the figure, the force $\left(F_{z, i}\right)$ and the mean mid-span displacement $\left(\delta_{z, i}\right)$, i.e. the mean value recorded by the two mid-span LVDTs, are normalised with respect to the maximum (failure) load of the S-type specimens $\left(F_{\text {zmax }} S\right)$ and the corresponding displacement $\left(\delta_{z \max } S\right)$, respectively. As a preliminary comment, it can be appreciated the great repetitively of the test results and the influence of the perforations that remarkably affects both stiffness and resistance of the specimens.

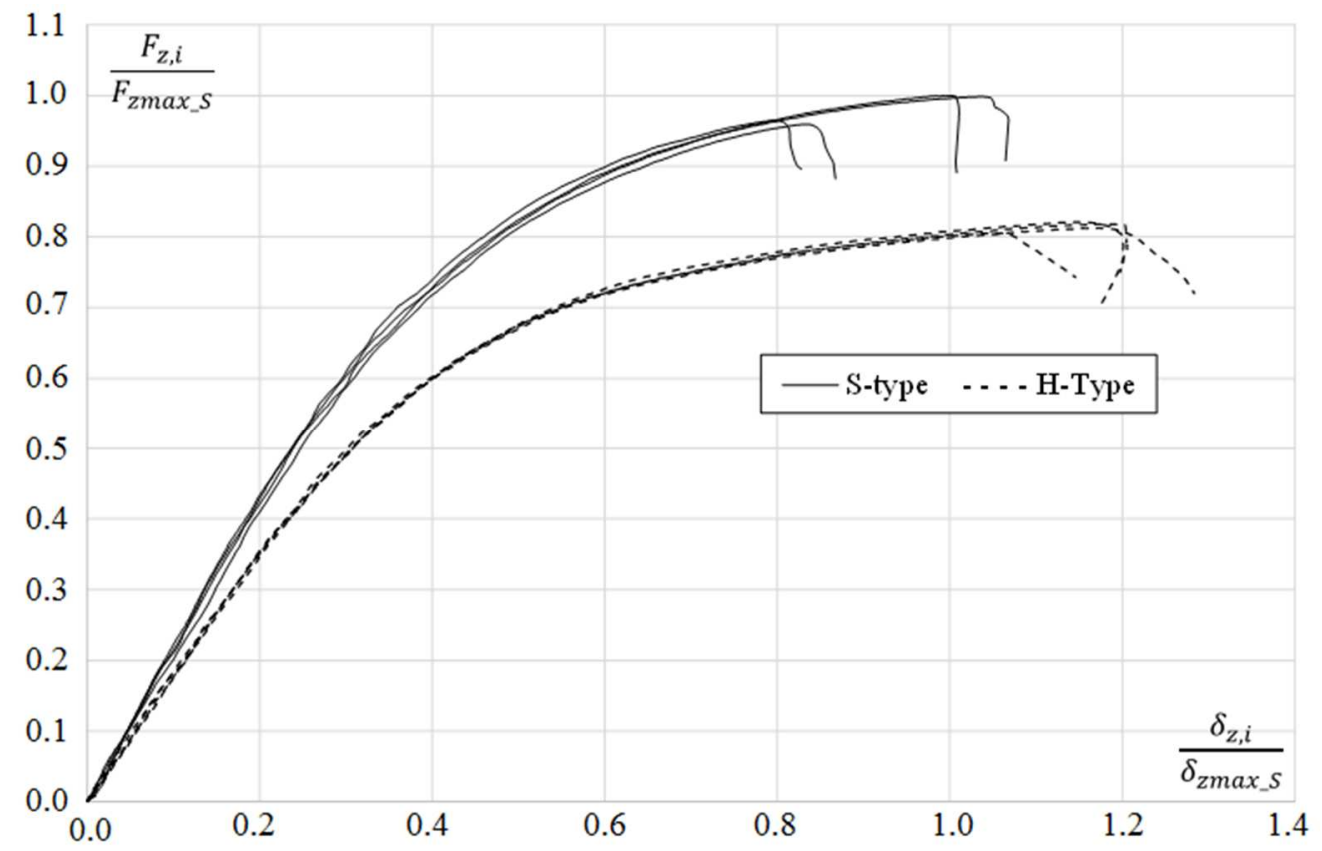

Figure 16. Load-mid-span displacement curves for the S-type and H-type profiles.

Tests results can be, at first, analysed in terms of flexural resistance, i.e. by considering the maximum bending moment $\left(M_{y, i}\right)$, which is reported in table 4 together with the mean $\left(M_{y, m}\right)$, standard deviation (st.dev) and characteristic values $\left(M_{y, k}\right)$. All these data are presented in non-dimensional form by dividing for the nominal elastic flexural resistance of the gross cross-section $M_{e l y}=W_{g, y} \cdot f_{y}$, where $W_{g, y}$ is the section modulus of the gross cross-section along the y-axis and $f_{y}$ is the mean value of the yielding strength. It has been decided to consider the elastic resistance for all bending cases only to propose the experimental data in a comparative manner, without any direct reference to the crosssection classification criteria of EC3 [43]. It can be noted that in case of S-type profiles, all the values 
are greater than unity confirming the importance of the strain-hardening effects induced by the cold production processes [9]. Furthermore, the influence of the perforations on the global resistance is non-negligible, leading to a reduction of $20 \%$ and $16 \%$ of the flexural resistance with reference to the mean and characteristic values, respectively.

Table 4. Non-dimensional ultimate bending moment along y-axis.

\begin{tabular}{|c|c|c|c|c|}
\hline specimen & $\frac{M_{y, i}}{M_{e l y}}$ & $\frac{M_{y, m}}{M_{e l y}}$ & st.dev & $\frac{M_{y, k}}{M_{e l y}}$ \\
\hline $\mathrm{S}_{1, \mathrm{y}}$ & 1.141 & \multirow{4}{*}{1.12} & \multirow{4}{*}{0.0263} & \multirow{4}{*}{1.06} \\
\hline$S_{2, y}$ & 1.144 & & & \\
\hline$S_{3, y}$ & 1.091 & & & \\
\hline $\mathrm{S}_{4, \mathrm{y}}$ & 1.103 & & & \\
\hline $\mathrm{H}_{1, \mathrm{y}}$ & 0.918 & \multirow{4}{*}{0.93} & \multirow{4}{*}{0.0081} & \multirow{4}{*}{0.91} \\
\hline $\mathrm{H}_{2, \mathrm{y}}$ & 0.926 & & & \\
\hline $\mathrm{H}_{3, \mathrm{y}}$ & 0.944 & & & \\
\hline $\mathrm{H}_{4, \mathrm{y}}$ & 0.925 & & & \\
\hline
\end{tabular}

The static scheme adopted for the tests in the non-symmetric direction is the same already presented in section 2.2.1 (Figure 13b) and, in order to prevent distortional phenomena, suitable restrains have been adopted at the specimen ends and at the load application points, as shown in Figure 16, allowing hence to simulate the effective layout of the upright frame.
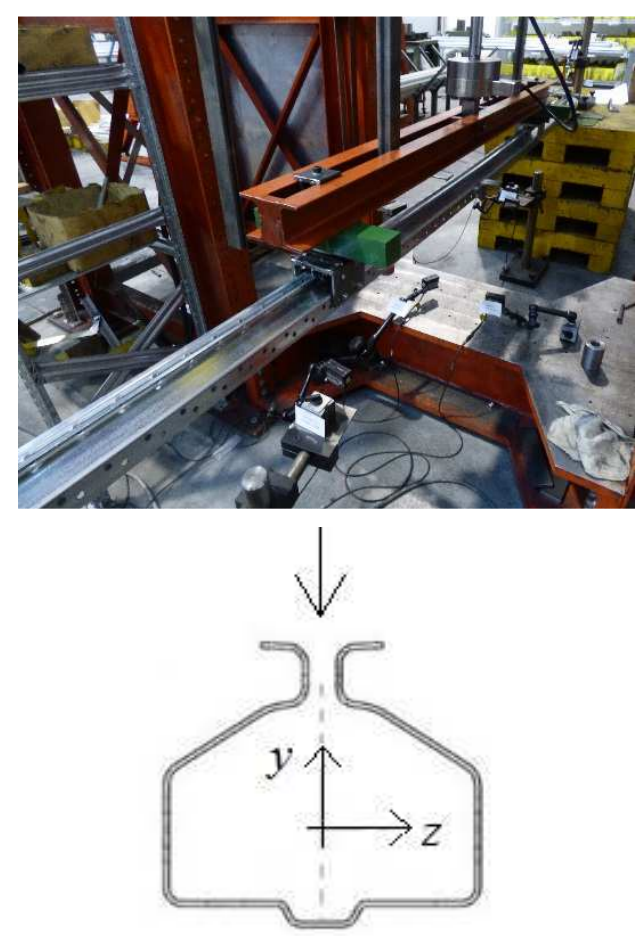

a)
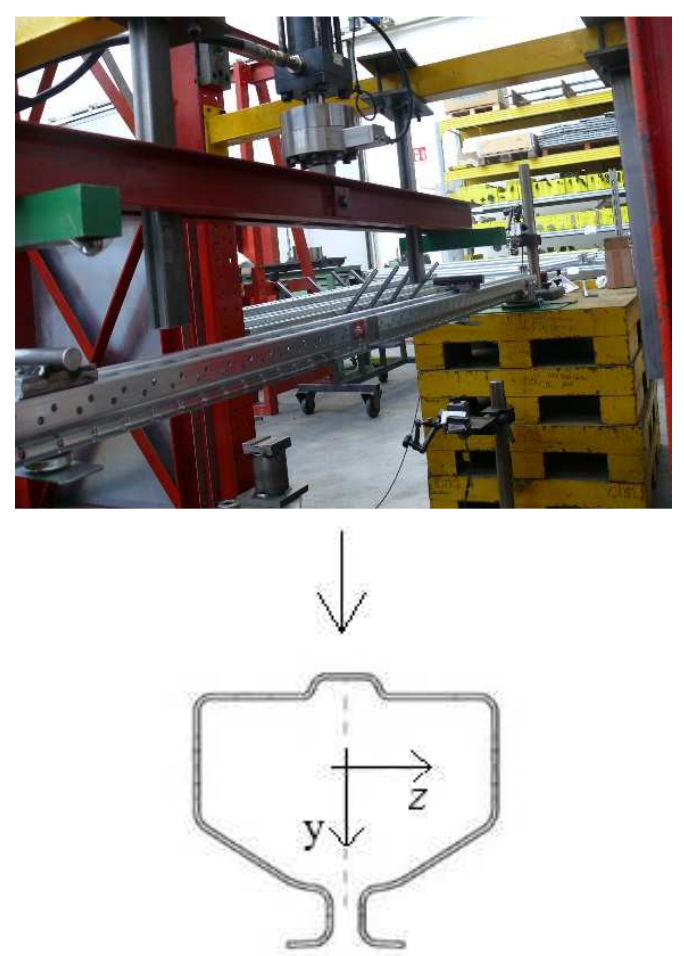

b)

Figure 17. Details of the test setup in both a) negative and b) positive directions. 

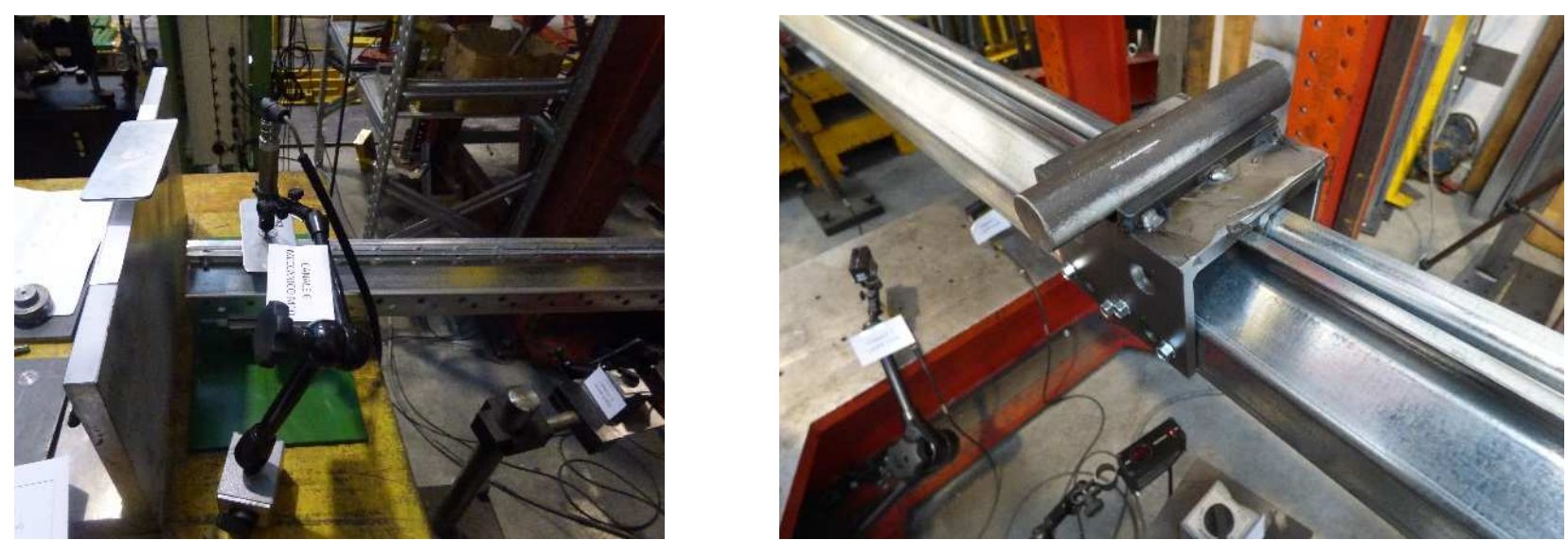

Figure 18. Local restrains used to avoid undesirable distortional effects.

Collapse occurred always in the constant bending moment zone, i.e. between the applied loads for both the positive and negative series of tests (Figure 19), like for the down-aisle bending tests.

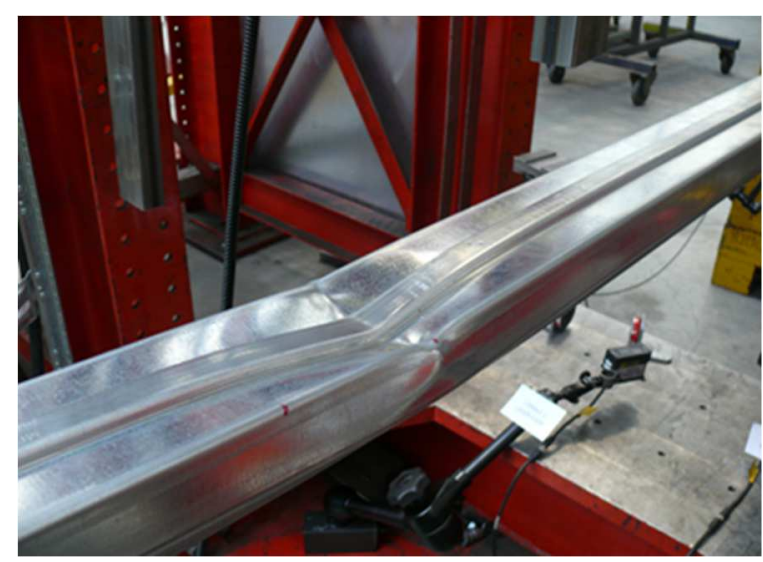

a)

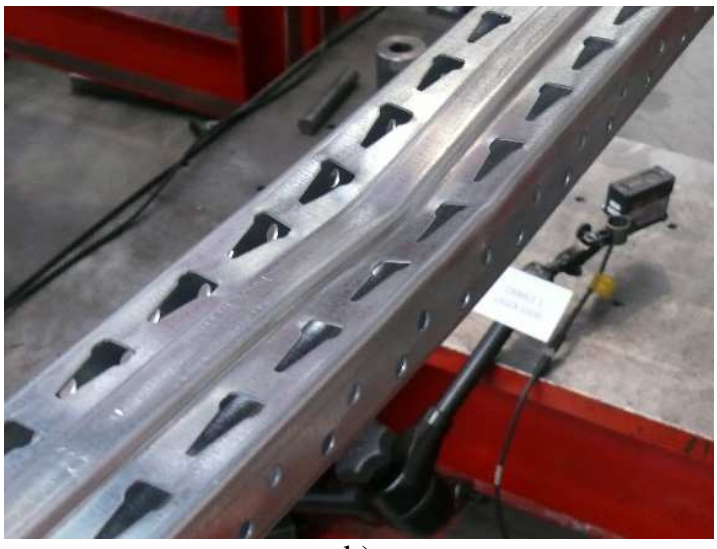

b)

Figure 19. Collapse after the bending test: a) the S-type and b) the H-type specimens

It can be noted that different boundary conditions have been used to realize the external supports in case of bending in the non-symmetric direction (Figure 20). In case of negative bending (Figure 20a), the web is directly supported by a steel plate located on a pin while, for positive bending (Figure 20b), suitable lateral plates have been bolted to the upright flanges, owing to the impossibility to load directly the rear ends of the upright. This device causes a secondary bending moment due to the eccentricity of the support point to the centroid.

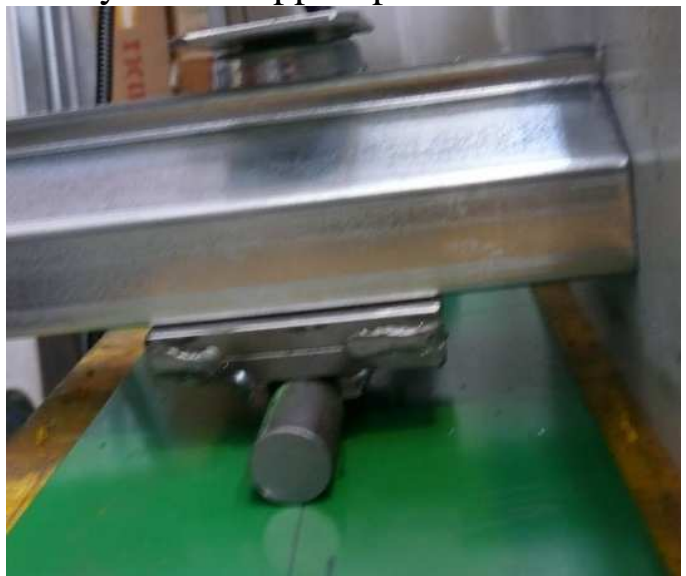

a)

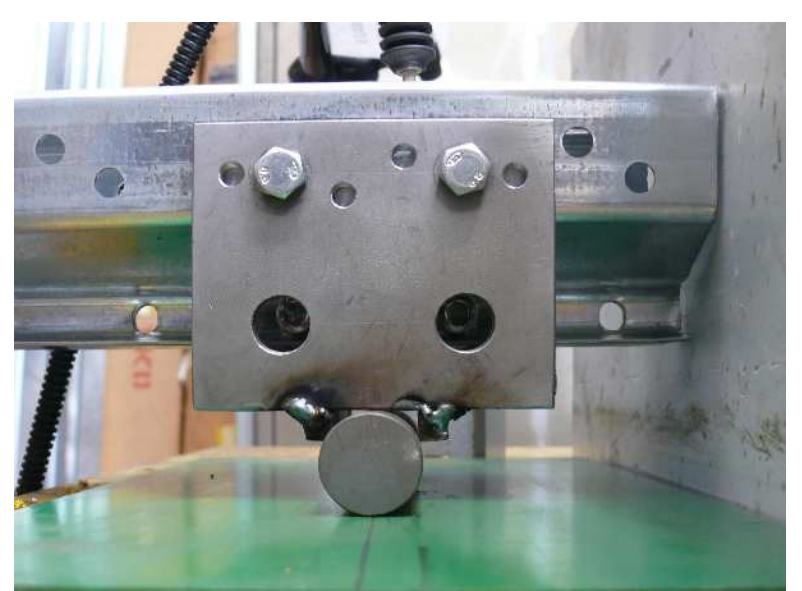

b)

Figure 20. End supports for positive (a) and negative (b) bending tests. 
The different boundary restraint conditions affect the stiffness of the elastic branch of the specimens as shown by the experimental curves presented in Figure 21, that shows the non-dimensional load $\left(F_{y}\right)$ vs. mid-span section displacement $\left(\delta_{y}\right)$ curves, for both the unperforated (S-type) and perforated (H-type) profiles by considering the positive (black) and negative (red) responses with solid and dashed lines related to $\mathrm{S}$ - and H-type profiles, respectively. The curves are normalized with respect to the maximum force $\left(F_{y m a x \_} S_{-} p o s\right)$ and to the associated displacement $\left(\delta_{y m a x} S_{-} p o s\right)$ achieved in the 7 tests of the S-type profiles for positive bending. As expected, perforations affect in a non-negligible 8 way both stiffness and resistance. Furthermore, it is worth noting that stiffness in the elastic branch is significantly influenced by the sign (positive or negative) of the bending moment.

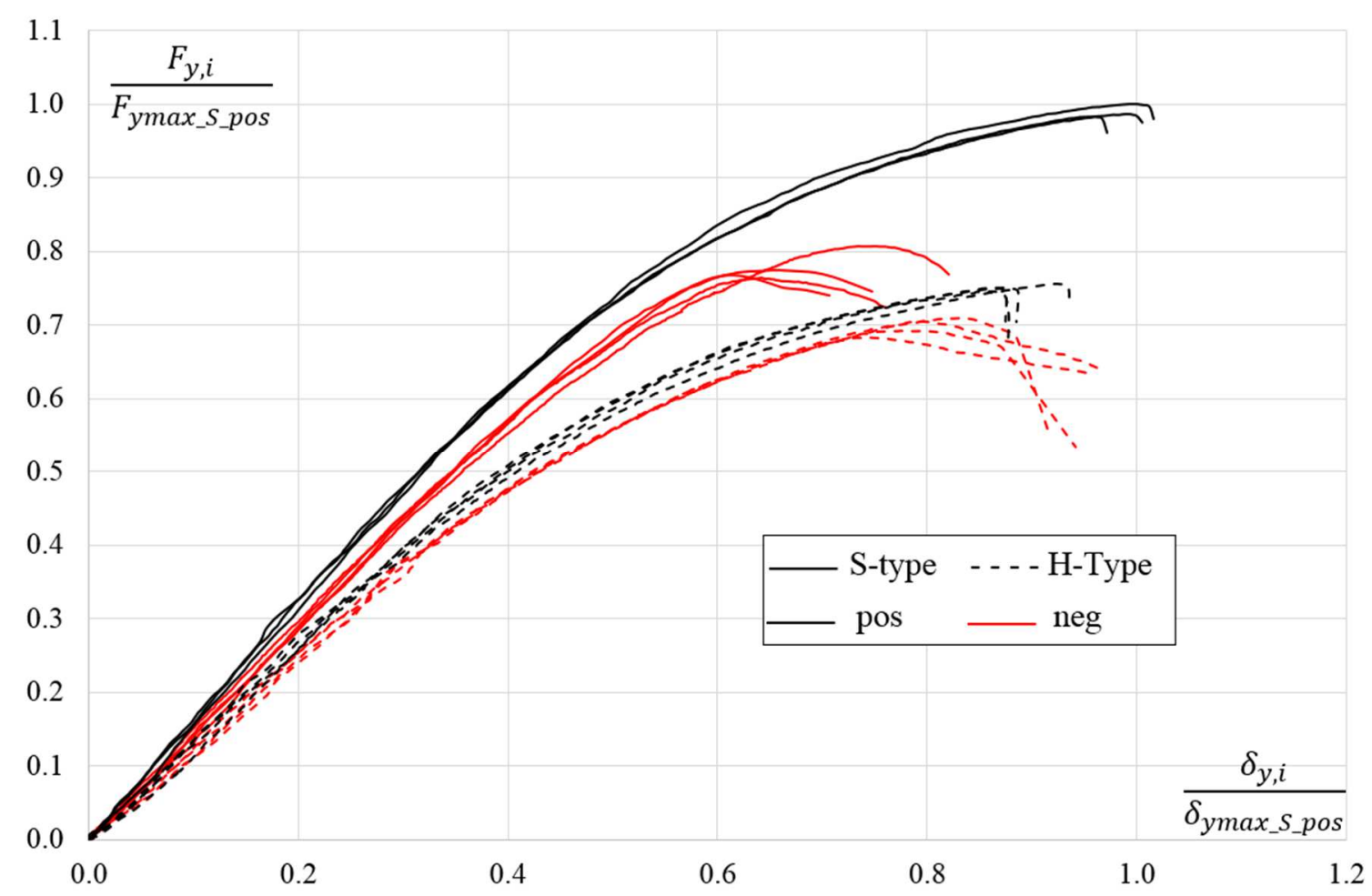

Figure 21. Non-dimensional force-displacement curves for S-type and H-type specimens.

For a better appraisal of the test outcomes, the results are presented in terms of failure bending moment as shown in Table 5, reporting the maximum experimental bending moment for each $i$ - test $\left(M_{z, i}\right)$ and, for each set of nominally equal specimens, the mean value $\left(M_{z, m}\right)$, the standard deviation (st.dev) and the characteristic value $\left(M_{z, k}\right)$. These data are normalized with respect to the nominal flexural resistance of the gross cross-section evaluated as $M_{e l z}=W_{g, \min , z} \cdot f_{y}$, where $W_{g, \min , z}$ is the minimum value of the gross section modulus along $\mathrm{z}$ - axis and $f_{y}$ is the mean yielding strength. It can be noted that, like for bending tests in the down-aisle direction non-dimensional data are proposed with reference to the elastic resistance.

Table 5. Non-dimensional ultimate bending moment along $\mathrm{z}$-axis for both positive and negative directions.

\begin{tabular}{|c|c|c|c|c|c|c|c|c|}
\hline & \multicolumn{4}{|c|}{ Positive moments } & \multicolumn{4}{|c|}{ Negative moments } \\
\hline specimen & $\frac{M_{z, p o s, i}}{M_{e l z}}$ & $\frac{M_{z, p o s, m}}{M_{\text {elz }}}$ & st.dev & $\frac{M_{z, p o s, k}}{M_{\text {elz }}}$ & $\frac{M_{z, n e g, i}}{M_{\text {elz }}}$ & $\frac{M_{z, n e g, m}}{M_{\text {elz }}}$ & st.dev & $\frac{M_{z, n e g, k}}{M_{\text {elz }}}$ \\
\hline $\mathrm{S}_{1}$ & 1.331 & \multirow{4}{*}{1.34} & \multirow{4}{*}{0.0095} & \multirow{4}{*}{1.31} & 1.031 & \multirow{4}{*}{1.05} & \multirow{4}{*}{0.0263} & \multirow{4}{*}{0.99} \\
\hline $\mathrm{S}_{2}$ & 1.332 & & & & 1.085 & & & \\
\hline $\mathrm{S}_{3}$ & 1.354 & & & & 1.041 & & & \\
\hline $\mathrm{S}_{4}$ & 1.348 & & & & 1.051 & & & \\
\hline $\mathrm{H}_{1}$ & 1.021 & 1.01 & 0.0050 & 1.00 & 0.932 & 0.94 & 0.0183 & 0.90 \\
\hline
\end{tabular}




\begin{tabular}{|l|l|l|l|l|}
\hline $\mathrm{H}_{2}$ & 1.015 & & & 0.925 \\
\hline $\mathrm{H}_{3}$ & 1.014 \\
\hline $\mathrm{H}_{4}$ & 1.011 & & 0.959 \\
& & 0.954 & & \\
\hline
\end{tabular}

1

Like in the previous tests, strain hardening effects play a non-negligible role on the solid cross-section resistance, up to $34 \%$ and $5 \%$ for positive and negative tests, respectively, related to the elastic bending resistance. For perforated components, despite the presence of holes/slots, the performance compared to the elastic gross cross-section resistance is moderately reduced (no more than $8 \%$ ) in case of negative moments, while a limited increment, between $1 \%$ and $2 \%$, is observed for positive moments. The influence of the perforations on the bending resistance is non-negligible: the mean bending moment is reduced of $33 \%$ and $12 \%$ for the positive and negative cases, respectively. If the characteristic values are considered, this reduction is $31 \%$ and $10 \%$ for the positive and negative cases, respectively.

\section{REMARKS ON THE EFFECTIVE AREA}

The value of the effective cross-sectional area is of paramount importance for the design of steel rack uprights, remarkably influencing the load carrying capacity of the overall frame. This data can be obtained by means of stub-column tests, i.e. compression tests on specimens having a short length [34]. From the practical point view, designers prefer to define the upright performance by making reference to the already introduced $Q$ parameter, that is herein considered for the discussion on the effective area. As it appears from Table 2, with reference to the $300 \mathrm{~mm}$ specimens of length and to the characteristic value, $Q$, assumes the values of 0.87 and 0.70 for solid and perforated specimens, respectively. These values confirm the remarkable influence of local buckling on the upright performance and point out the quite high reduction of effective section due to the presence of perforations. Furthermore, the updated version of EN15512 [35], which is currently under public enquiry before the official approval by CEN (European Committee for Standardization), provides in Annex $G$ a procedure addressed to obtain the effective geometry of profiles taking into account the presence of regularly distributed perforations. In particular, reference is made to an equivalent solid cross section and the effect of the perforations due to holes and/or slots is accounted for by means of local thickness reductions (Figure 22). As declared in the code, values calculated by this method are acceptable for stiffness and may be used in global models while strength values should be obtained by testing according to the requirements of this standard.
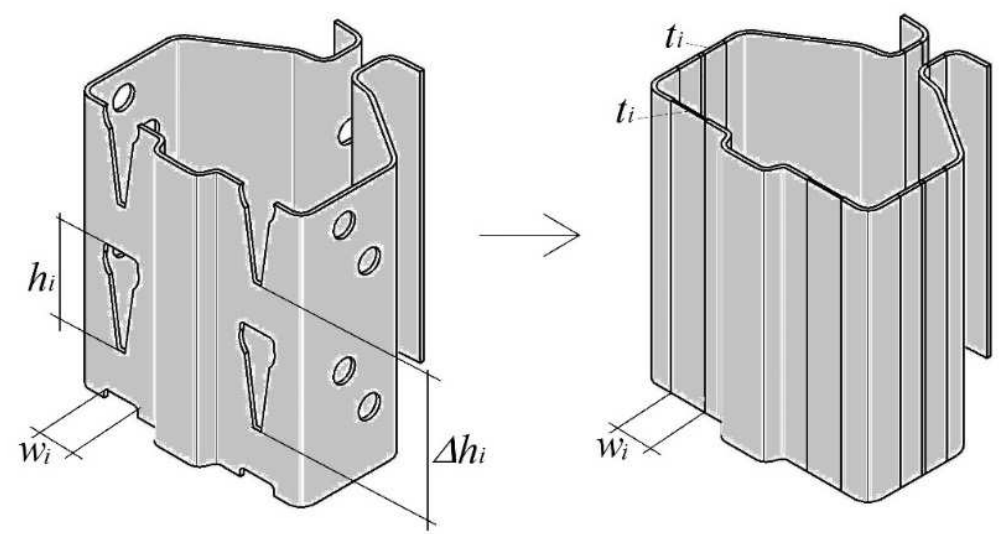

Figure 22. Evaluation of the equivalent cross-section, according to [35].

According to the proposed procedure, the equivalent thickness $\left(t_{i}\right)$, is defined starting from the initial 


$$
t_{i}=t \frac{\Delta h_{i}-h_{i}-\xi_{i} w_{i}}{\Delta h_{i}}
$$

where $w_{i}$ and $h_{i}$ are the width and the height of a generic rectangular hole and $\Delta h_{i}$ is the constant step between pitches along the member.

It can be noted that for circular holes both $h_{i}$ and $w_{i}$ are assumed equal to the diameter $d$. In case of non-regular slots, like the ones on the front of the considered upright, reference has been made to their maximum dimensions in terms of height and width. The term $\xi_{i}$ is defined as:

$$
\xi_{i}=\frac{\Delta h_{i}-h_{i}}{2 w_{i}} \leq 1.5
$$

By applying this procedure, the associated $Q$ value, for the considered perforated profile, is 0.77 , approximately $10 \%$ greater than the one experimentally evaluated. It is worth noting that the use of the minimum perforated area that was adopted in the past for routine design, in absence of stubcolumn test data, provides a $Q$ value of 0.79 , that is however from the unsafe side, being $15 \%$ greater than the experimental one. Consequently, stub-column tests appear as necessary for a safe and reliable design.

\section{REMARKS ON THE EFFECTIVE SECOND MOMENT OF AREA}

The European rack provisions, including also the prEN [35] version, and the US one [10] indicate the experimental approach as a suitable and reliable way for the evaluation of the bending resistance of uprights. Nevertheless, these codes do not provide details about the procedure to be adopted for the evaluation of the second-moment of area $\left(I_{e f f}\right)$, that is a key parameter for both static and seismic design. Owing to the quite limited additional cost for monitoring the vertical displacements during tests, it seems very convenient to improve the guidelines for bending tests including also additional recommendations for the evaluation of the beam flexural stiffness along the principal axes.

Starting from the bending test results discussed in the previous section, attention has been focussed on the evaluation of $I_{\text {eff. }}$ To this aim, the first branch of the experimental curves (Figures 16 and 21) characterised by a quite linear force-displacement relationship was considered. With reference to the static scheme of Figure 13b, a basic equation deriving from the elastic theory of structures has been adopted to assess $I_{\text {eff, }}$, where $k$ indicates the axis of flexure (i.e. y, z-pos or z-neg). In particular, for each couple of applied load $\left(F_{j}\right)$ and associated displacement of the mid-span section $\left(\delta_{j}\right), I_{e f f, k}$ has been evaluated by neglecting the shear deformability contribution, owing to the high specimen slenderness, as:

$$
I_{e f f, k}=\frac{F_{j}}{2 E \delta_{j}} a\left(\frac{L^{2}}{8}-\frac{a^{2}}{6}\right)
$$

where, $L$ and $a$ are the span of the beam and the distance between the support and the load lines and $E$ is the Young's modulus.

Equation 3) is applied to each of the load-displacement curves following three different methods, each of them related to the elastic ranges $\left[10 \% \mathrm{~F}_{\mathrm{u}}-\alpha \mathrm{F}_{\mathrm{u}}\right.$ ], with $\alpha$ ranging from $30 \%$ to $70 \%$ and with $\mathrm{F}_{\mathrm{u}}$ maximum load achieved in the test. Referring to Figure 23, it can be noted that:

- according to method 1 (Figure 23b), for each point $\left(\delta_{j}, F_{j}\right)$ of load-displacement curve, the term $I_{\text {eff }, k, i}$ is directly evaluated according to eq. 3 . The mean value $\left(I_{\text {eff }, k}\right)$ of all the $I_{\text {eff }, k, i}$ values is assumed as representative of the considered range;

- according to method 2 (Figure 23c), the experimental curve is approximated via a linear regression function. The slope of the function $\left(K_{f}\right)$ relates the increment of force $\left(\Delta F_{k}\right)$ and the displacement $\left(\Delta \delta_{k}\right)$ as: 


$$
\Delta F_{k}=K_{f} \Delta \delta_{k}
$$

Rewriting Eq. 3) in incremental form, it can be obtained:

$$
I_{e f f, k}=\frac{\Delta F_{k}}{2 E \Delta \delta_{k}} a\left(\frac{L^{2}}{8}-\frac{a^{2}}{6}\right)
$$

By combining eqs. 4) and 5), $I_{e f f, k}$ is given by the expression:

$$
I_{e f f, k}=\frac{K_{f}}{2 E} a\left(\frac{L^{2}}{8}-\frac{a^{2}}{6}\right)
$$

- according to method 3 (Figure 23d), reference is made to the slope $\left(K_{f}\right)$ of the secant of the experimental curve, based on the first and last point in the considered reference range. Consequently, the second moment of area is evaluated as in Equation 6).

All these methods have been applied with reference to different amplitude of the ranges of experimental data, i.e. from $10 \% \mathrm{~F}_{\mathrm{u}}-30 \% \mathrm{~F}_{\mathrm{u}}$ to $10 \% \mathrm{~F}_{\mathrm{u}}-70 \% \mathrm{~F}_{\mathrm{u}}$.

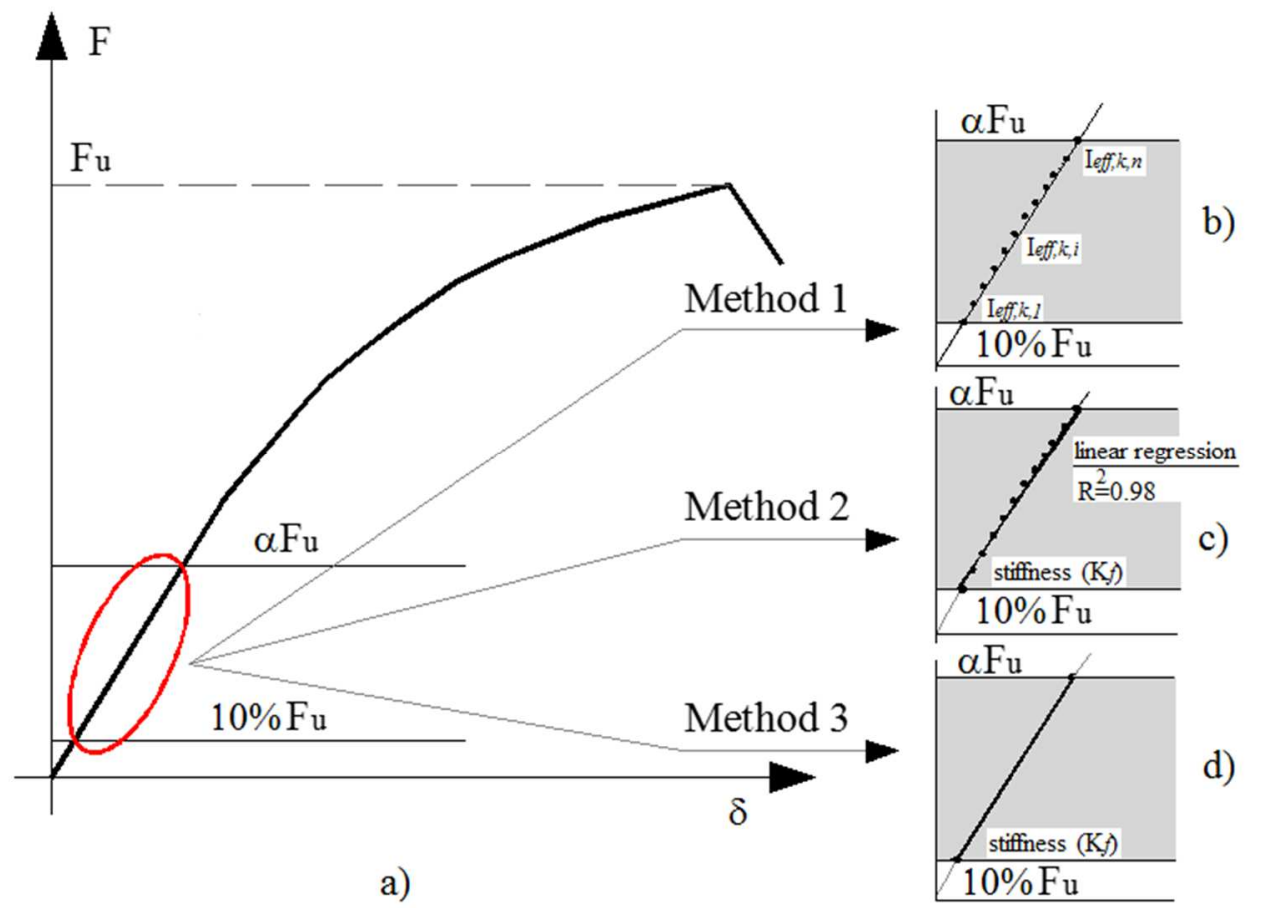

Figure 23. Methods for the evaluation of the second moment of area: a) the experimental curve, b) method 1, c) method 2 and $\mathrm{d}$ ) method 3.

Table 6. $I_{e f f, k} / I_{g, k}$ ratio associated with method 1.

Results associated with the proposed methods are reported in Tables $6(\operatorname{method} 1), 7(\operatorname{method} 2)$ and 8 (method 3), in terms of ratio between the effective second-moment of area and the theoretical gross one $\left(I_{g, k}\right)$ in the $k$-direction, i.e. $I_{e f f, k} / I_{g, k}$ ratio. In addition to the values evaluated by considering the

\begin{tabular}{|c|c|c|c|c|c|c|c|c|c|c|}
\hline & & & \multicolumn{4}{|c|}{$E=210000 \mathrm{MPa}$} & \multicolumn{4}{|c|}{$E=180500 \mathrm{MPa}$} \\
\hline & axis & range & $10 \%-30 \%$ & $10 \%-50 \%$ & $10 \%-60 \%$ & $10 \%-70 \%$ & $10 \%-30 \%$ & $10 \%-50 \%$ & $10 \%-60 \%$ & $10 \%-70 \%$ \\
\hline \multirow{6}{*}{$\mathbf{S}$} & \multirow[b]{2}{*}{$\mathrm{y}$} & mean & 0.89 & 0.88 & 0.88 & 0.84 & 1.02 & 1.02 & 1.01 & 0.97 \\
\hline & & st.dev. & 0.0281 & 0.0261 & 0.0222 & 0.0316 & 0.0324 & 0.0300 & 0.0256 & 0.0364 \\
\hline & \multirow{2}{*}{$\begin{array}{c}\mathrm{Z}^{-} \\
\text {neg }\end{array}$} & mean & 0.83 & 0.84 & 0.84 & 0.84 & 0.97 & 0.98 & 0.98 & 0.98 \\
\hline & & st.dev. & 0.0318 & 0.0239 & 0.0211 & 0.0187 & 0.0369 & 0.0277 & 0.0244 & 0.0217 \\
\hline & \multirow{2}{*}{$\begin{array}{l}\mathrm{z}- \\
\text { pos }\end{array}$} & mean & 0.94 & 0.94 & 0.94 & 0.93 & 1.09 & 1.09 & 1.09 & 1.08 \\
\hline & & st.dev. & 0.0305 & 0.0227 & 0.0186 & 0.0150 & 0.0354 & 0.0263 & 0.0215 & 0.0173 \\
\hline
\end{tabular}
modulus of elasticity recommended by the steel design provisions (i.e. $E=210000 \mathrm{MPa}$ ), also the actual value (approximately 14\% lower) has been considered for the three methods. 


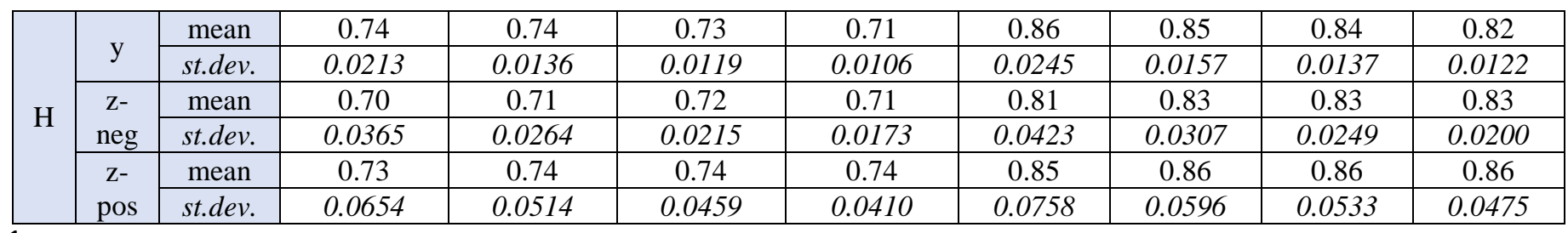

1

3

4

5

6

Table 7. $I_{e f f, k} / I_{g, k}$ ratio associated with method 2.

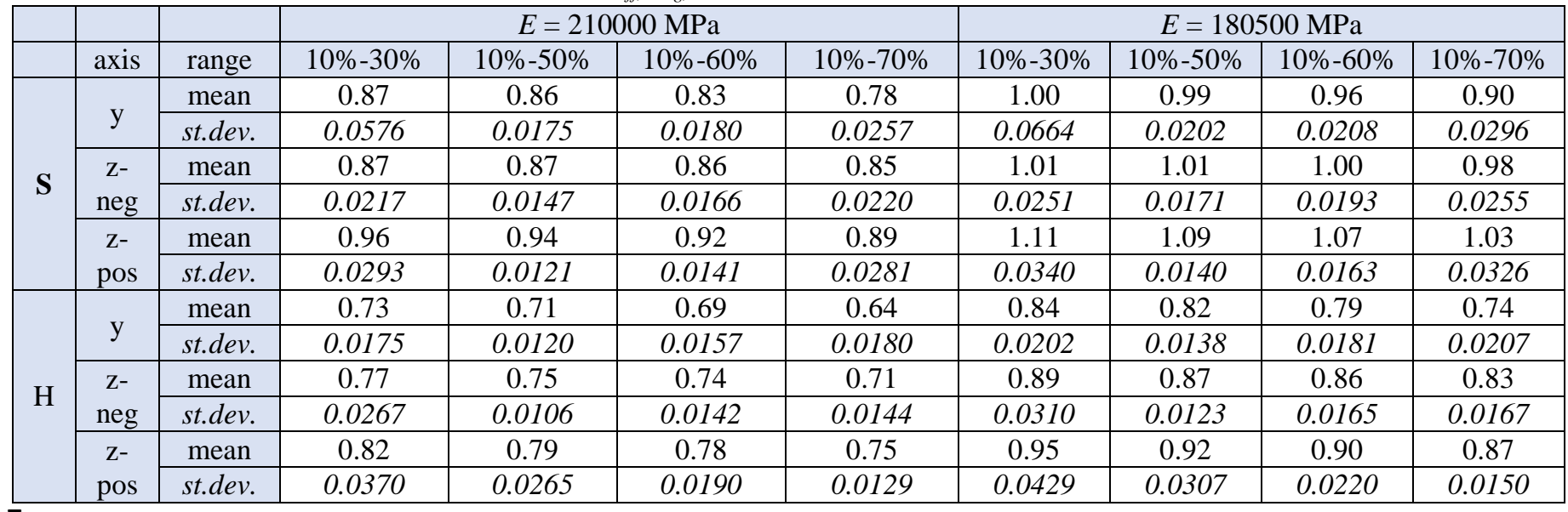

7

8

Table 8. $I_{\text {eff }, k} / I_{g, k}$ ratio associated with method 3.

\begin{tabular}{|c|c|c|c|c|c|c|c|c|c|c|}
\hline & & & \multicolumn{4}{|c|}{$E=210000 \mathrm{MPa}$} & \multicolumn{4}{|c|}{$E=180500 \mathrm{MPa}$} \\
\hline & axis & range & $10 \%-30 \%$ & $10 \%-50 \%$ & $10 \%-60 \%$ & $10 \%-70 \%$ & $10 \%-30 \%$ & $10 \%-50 \%$ & $10 \%-60 \%$ & $10 \%-70 \%$ \\
\hline \multirow{6}{*}{$\mathbf{S}$} & & mean & 0.89 & 0.85 & 0.82 & 0.77 & 1.02 & 0.98 & 0.94 & 0.89 \\
\hline & $\mathrm{y}$ & st.dev. & 0.0633 & 0.0245 & 0.0246 & 0.0285 & 0.0730 & 0.0282 & 0.0283 & 0.0329 \\
\hline & $\mathrm{z}-$ & mean & 0.87 & 0.87 & 0.85 & 0.84 & 1.01 & 1.00 & 0.99 & 0.97 \\
\hline & neg & st.dev. & 0.0125 & 0.0112 & 0.0118 & 0.0183 & 0.0144 & 0.0130 & 0.0136 & 0.0213 \\
\hline & $\mathrm{z}-$ & mean & 0.97 & 0.94 & 0.91 & 0.87 & 1.13 & 1.09 & 1.06 & 1.01 \\
\hline & pos & st.dev. & 0.0305 & 0.0114 & 0.0120 & 0.0114 & 0.0353 & 0.0132 & 0.0140 & 0.0132 \\
\hline \multirow{6}{*}{$\mathrm{H}$} & & mean & 0.74 & 0.70 & 0.67 & 0.63 & 0.85 & 0.80 & 0.77 & 0.72 \\
\hline & y & st.dev. & 0.0222 & 0.0113 & 0.0139 & 0.0111 & 0.0256 & 0.0130 & 0.0160 & 0.0128 \\
\hline & z- & mean & 0.77 & 0.75 & 0.73 & 0.70 & 0.89 & 0.86 & 0.85 & 0.81 \\
\hline & neg & st.dev. & 0.0168 & 0.0186 & 0.0175 & 0.0087 & 0.0195 & 0.0216 & 0.0203 & 0.0101 \\
\hline & $\mathrm{z}-$ & mean & 0.82 & 0.79 & 0.77 & 0.73 & 0.95 & 0.92 & 0.89 & 0.85 \\
\hline & pos & st.dev. & 0.0175 & 0.0093 & 0.0039 & 0.0060 & 0.0203 & 0.0108 & 0.0045 & 0.0070 \\
\hline
\end{tabular}

9

10 Mean value (mean) and the standard deviation (st. dev.) associated with the elaboration of each curve 11 according to these three methods are reported by considering the data related to nominally equal specimens. Furthermore, in order to investigate the influence of the range of data on the results, the maximum (MAX) versus minimum (min) ratio is reported, too. In particular, it can be noted that:

- the value of the effective second moment of area depends on the range of the considered data. Increasing the extension of the considered zone, $I_{e f f, k}$ in general decreases, as expected, owing to the material non-linearity and the stress concentration associated with the cross-section type;

- unlike what found for the bending resistance, by using the nominal value of the $E$, the $I_{e f f, k}$ $I_{g, k}$ ratios are always lower than unity, showing the influence of local buckling also for low load levels. If solid members are considered, the ratios are comprised between 0.77 and 0.97 , while in case of perforated members, the ratio ranges between 0.63 and 0.82 . By using the 
effective $E$ value $I_{e f f, k} / I_{g, k}$ term ranges between 0.89 and 1.13 while for perforated it is between 0.72 and 0.95

- method 1 is the most stable: the $\mathrm{MAX} / \mathrm{min}$ ratio with reference to the proposed data is always lower than $6 \%$, while for the other methods it ranges up to $18 \%$;

- the largest range $\left(10 \%-70 \% \mathrm{~F}_{\mathrm{u}}\right)$ is significantly interested by non-linear behaviour and hence should not be considered for the effective stiffness evaluation (and hence, in the following, it is neglected for the outcome discussion);

- if the $10 \%-70 \%$ range is excluded, the $\mathrm{MAX} / \mathrm{min}$ ratio decreases remarkably for each method and became lower than $3 \%, 7 \%$ and $10 \%$ for method 1, 2 and 3, respectively, independently of the considered $E$ value.

Moreover, it can be noted that in case of bending along the non-symmetry axis ( $\mathrm{z}$-axis according to Table 1), the state of stress acting on the rear flanges (or, equivalently, on the other zones of the crosssection) influences not only the resistance but also the second moment of area, issue that is currently neglected in routine design as well as in standards codes. For a more deep analysis of the results, reference can be made to the ratio between the second moment of area associated with the z-neg $\left(I_{\text {eff, }, \text { neg }}\right)$ and z-pos $\left(I_{\text {eff,z,pos }}\right)$ appraised by tests. In table 9, this ratio is presented for the different elastic ranges and for each analysis method. Difference in terms of effective second moment of area is up to, in mean, $11 \%$ and $6 \%$ for the solid and the perforated cross-section, respectively, confirming the importance of the role played by the support conditions on the global behaviour of the upright in bending.

Table 9. $I_{\text {eff,z,neg }} / I_{\text {eff, }, \text {,pos }}$ ratio for the considered S- and H-type specimen.

\begin{tabular}{|c|c|c|c|c|c|}
\hline 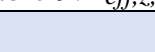 & & \multicolumn{3}{|c|}{ Range } & mean \\
\hline & & $10 \%-30 \%$ & $10 \%-50 \%$ & $10 \%-60 \%$ & \\
\hline \multirow{2}{*}{ Method 1} & S-type & 0.88 & 0.89 & 0.90 & 0.89 \\
\hline & H-type & 0.96 & 0.96 & 0.96 & 0.96 \\
\hline \multirow{2}{*}{ Method 2} & S-type & 0.91 & 0.93 & 0.94 & 0.92 \\
\hline & H-type & 0.93 & 0.94 & 0.96 & 0.94 \\
\hline \multirow{2}{*}{ Method 3} & S-type & 0.87 & 0.92 & 0.94 & 0.91 \\
\hline & H-type & 0.94 & 0.94 & 0.95 & 0.94 \\
\hline
\end{tabular}

Furthermore, the second moments of area associated with the S-type and the H-type specimens have been compared with the aim of investigating the influence of the holes. The results presented in Table 10 , in terms of $I_{\text {eff, }, k_{-} S} / I_{\text {eff, } k_{-} H}$ ratios, show a non-negligible influence of the perforation system on the flexural behaviour. For the considered upright differences for method 1 range from $13 \%$ to $20 \%$ for the bending along z-pos and y direction, respectively. These differences increase if method 2 or method 3 is considered.

Table 10. $I_{e f f, k, \_S} / I_{e f f, k \_H}$ ratio for each direction.

\begin{tabular}{|c|c|c|c|c|c|c|}
\hline \multirow{2}{*}{ Method } & \multirow{2}{*}{ axis } & & \multicolumn{3}{|c|}{ Range } & \multirow{2}{*}{ mean } \\
\hline & & & $10 \%-30 \%$ & $10 \%-50 \%$ & $10 \%-60 \%$ & \\
\hline \multirow{6}{*}{1} & \multirow[b]{2}{*}{$\mathrm{y}$} & mean & 1.20 & 1.20 & 1.20 & 1.20 \\
\hline & & st.dev. & 0.0353 & 0.0229 & 0.0146 & \\
\hline & \multirow{2}{*}{ Z-neg } & mean & 1.19 & 1.18 & 1.18 & 1.18 \\
\hline & & st.dev. & 0.0819 & 0.0551 & 0.0459 & \\
\hline & \multirow{2}{*}{ Z-pos } & mean & 1.30 & 1.27 & 1.26 & 1.29 \\
\hline & & st.dev. & 0.1594 & 0.1153 & 0.0989 & \\
\hline \multirow{6}{*}{2} & \multirow[b]{2}{*}{$\mathrm{y}$} & mean & 1.18 & 1.21 & 1.21 & 1.20 \\
\hline & & st.dev. & 0.0855 & 0.0264 & 0.0512 & \\
\hline & \multirow{2}{*}{ z-neg } & mean & 1.14 & 1.16 & 1.16 & 1.15 \\
\hline & & st.dev. & 0.0446 & 0.0290 & 0.0416 & \\
\hline & \multirow{2}{*}{ Z-pos } & mean & 1.17 & 1.18 & 1.18 & 1.18 \\
\hline & & st.dev. & 0.0898 & 0.0511 & 0.0464 & \\
\hline
\end{tabular}




\begin{tabular}{|c|c|c|c|c|c|c|}
\hline \multirow{3}{*}{3} & \multirow{2}{*}{$\mathrm{y}$} & mean & 1.20 & 1.23 & 1.22 & 1.22 \\
\cline { 2 - 7 } & & st.dev. & 0.0903 & 0.0446 & 0.0575 & \\
\cline { 2 - 7 } & \multirow{2}{*}{ z-neg } & mean & 1.13 & 1.16 & 1.17 & 1.15 \\
\cline { 2 - 7 } & & st.dev. & 0.0096 & 0.0428 & 0.0301 & \\
\cline { 2 - 7 } & \multirow{2}{*}{ z-pos } & mean & 1.19 & 1.19 & 1.18 & 1.18 \\
\cline { 3 - 7 } & & st.dev. & 0.0623 & 0.0281 & 0.0150 & \\
\hline
\end{tabular}

1 Finally, the experimental second moments of area $\left(I_{e f f, k}\right)$ of the H-type specimens obtained by the 2 three methods, are compared with two different theoretical values: i) $I_{e q, k}$ obtained from the equivalent 3 cross-section (Figure 19), according to ref. [37], and ii) $I_{n e t, k}$ obtained by considering the maximum 4 perforated cross-section (cs. 2 in Figure 4). The results, presented in table 11 in terms of ratios $I_{\text {eff, } k,} /$ $5 I_{e q, k}$ and $I_{e f f, k} / I_{n e t, k}$, show that theoretical approaches lead to an average overestimation of the second 6 moments of area. This trend, observable for all the considered cases, is not true for the z-pos direction 7 for methods 2 and 3. Furthermore, if method 1 is considered, it can be noted that the equivalent cross8 section approach tends to an overestimation greater than the one obtained from the net section. 9 Conversely, for method 2 or 3 no general indications can be found.

Table 11. Comparison between experimental and theoretical second moment of area for H-type members.

\begin{tabular}{|c|c|c|c|c|c|c|c|c|c|}
\hline & & & & \multicolumn{3}{|c|}{$E=210000 \mathrm{MPa}$} & \multicolumn{3}{|c|}{$E=180500 \mathrm{MPa}$} \\
\hline Method & & axis & & $10 \%-30 \%$ & $10 \%-50 \%$ & $10 \%-60 \%$ & $10 \%-30 \%$ & $10 \%-50 \%$ & $10 \%-60 \%$ \\
\hline \multirow{12}{*}{1} & \multirow{6}{*}{$\begin{array}{c}I_{\text {eff }, k} / \\
I_{e q, k}\end{array}$} & \multirow[b]{2}{*}{$\mathrm{y}$} & mean & 0.90 & 0.89 & 0.88 & 1.03 & 1.02 & 1.01 \\
\hline & & & st.dev. & 0.0256 & 0.0164 & 0.0143 & 0.0295 & 0.0189 & 0.0165 \\
\hline & & \multirow{2}{*}{ z-neg } & mean & 0.81 & 0.82 & 0.83 & 0.93 & 0.95 & 0.95 \\
\hline & & & st.dev. & 0.0421 & 0.0305 & 0.0248 & 0.0484 & 0.0351 & 0.0285 \\
\hline & & \multirow{2}{*}{ Z-pos } & mean & 0.90 & 0.92 & 0.92 & 0.97 & 0.99 & 0.99 \\
\hline & & & st.dev. & 0.1367 & 0.1349 & 0.1341 & 0.0868 & 0.0683 & 0.0610 \\
\hline & \multirow{6}{*}{$\begin{array}{c}I_{\text {eff }, k} / \\
I_{\text {net }, k}\end{array}$} & \multirow[b]{2}{*}{$\mathrm{y}$} & mean & 0.93 & 0.92 & 0.91 & 1.07 & 1.06 & 1.05 \\
\hline & & & st.dev. & 0.0267 & 0.0171 & 0.0149 & 0.0307 & 0.0196 & 0.0172 \\
\hline & & \multirow{2}{*}{ z-neg } & mean & 0.92 & 0.93 & 0.94 & 1.05 & 1.07 & 1.08 \\
\hline & & & st.dev. & 0.0478 & 0.0346 & 0.0281 & 0.0549 & 0.0398 & 0.0323 \\
\hline & & \multirow{2}{*}{ Z-pos } & mean & 0.96 & 0.97 & 0.97 & 1.10 & 1.12 & 1.12 \\
\hline & & & st.dev. & 0.0856 & 0.0673 & 0.0602 & 0.0985 & 0.0774 & 0.0692 \\
\hline \multirow{12}{*}{2} & \multirow{6}{*}{$\begin{array}{c}I_{e f f, k} / \\
I_{e q, k}\end{array}$} & \multirow[b]{2}{*}{$\mathrm{y}$} & mean & 0.88 & 0.86 & 0.83 & 1.01 & 0.99 & 0.95 \\
\hline & & & st.dev. & 0.0212 & 0.0144 & 0.0190 & 0.0243 & 0.0166 & 0.0218 \\
\hline & & \multirow{2}{*}{ z-neg } & mean & 0.88 & 0.87 & 0.86 & 1.02 & 1.00 & 0.99 \\
\hline & & & st.dev. & 0.0308 & 0.0123 & 0.0164 & 0.0355 & 0.0141 & 0.0189 \\
\hline & & \multirow{2}{*}{ Z-pos } & mean & 0.95 & 0.92 & 0.90 & 1.09 & 1.05 & 1.03 \\
\hline & & & st.dev. & 0.0427 & 0.0306 & 0.0219 & 0.0491 & 0.0352 & 0.0252 \\
\hline & \multirow{6}{*}{$\begin{array}{c}I_{\text {eff }, k} / \\
I_{n e t, k}\end{array}$} & \multirow[b]{2}{*}{$\mathrm{y}$} & mean & 0.83 & 0.81 & 0.81 & 0.96 & 0.93 & 0.93 \\
\hline & & & st.dev. & 0.0290 & 0.0115 & 0.0154 & 0.0333 & 0.0132 & 0.0177 \\
\hline & & \multirow{2}{*}{ z-neg } & mean & 1.00 & 0.98 & 0.97 & 1.15 & 1.13 & 1.12 \\
\hline & & & st.dev. & 0.0350 & 0.0139 & 0.0186 & 0.0402 & 0.0160 & 0.0214 \\
\hline & & \multirow{2}{*}{ Z-pos } & mean & 1.08 & 1.04 & 1.02 & 1.24 & 1.20 & 1.17 \\
\hline & & & st.dev. & 0.0485 & 0.0347 & 0.0249 & 0.0557 & 0.0399 & 0.0286 \\
\hline \multirow{12}{*}{3} & \multirow{6}{*}{$\begin{array}{c}I_{e f f, k} / \\
I_{e q, k}\end{array}$} & \multirow[b]{2}{*}{$\mathrm{y}$} & mean & 0.89 & 0.84 & 0.81 & 1.02 & 0.97 & 0.93 \\
\hline & & & st.dev. & 0.0268 & 0.0136 & 0.0167 & 0.0308 & 0.0156 & 0.0192 \\
\hline & & \multirow{2}{*}{ z-neg } & mean & 0.89 & 0.86 & 0.84 & 1.02 & 0.99 & 0.97 \\
\hline & & & st.dev. & 0.0194 & 0.0215 & 0.0202 & 0.0223 & 0.0247 & 0.0233 \\
\hline & & \multirow{2}{*}{ Z-pos } & mean & 0.94 & 0.91 & 0.89 & 1.08 & 1.05 & 1.02 \\
\hline & & & st.dev. & 0.0202 & 0.0107 & 0.0045 & 0.0233 & 0.0123 & 0.0051 \\
\hline & & & mean & 0.83 & 0.81 & 0.79 & 0.96 & 0.93 & 0.91 \\
\hline & & $\mathrm{y}$ & st.dev. & 0.0182 & 0.0202 & 0.0190 & 0.0210 & 0.0232 & 0.0218 \\
\hline & $I_{e f f, k} /$ & & mean & 1.01 & 0.98 & 0.96 & 1.16 & 1.12 & 1.10 \\
\hline & $I_{n e t, k}$ & z-neg & st.dev. & 0.0220 & 0.0244 & 0.0229 & 0.0253 & 0.0280 & 0.0264 \\
\hline & & 7-nคs & mean & 1.07 & 1.03 & 1.01 & 1.23 & 1.19 & 1.16 \\
\hline & & Z-pos & st.dev. & 0.0229 & 0.0122 & 0.0051 & 0.0264 & 0.0140 & 0.0058 \\
\hline
\end{tabular}




\section{Concluding remarks}

An extensive experimental campaign has been conducted on an open TWCF profile typically used as upright for storage solutions, mainly for adjustable pallet racks. Two different types of tests have been conducted: i) compression test on specimens having different lengths and ii) bending test on both the down-aisle and cross-aisle direction. In order to investigate the influence of the regular perforation systems that characterize the considered members, both perforated and unperforated (solid) profiles have been tested.

Compression tests were performed by adopting an alternative specimen set-up, differing for the end restraints usually suggested by standards, able to guarantee a high level of repeatability. Test results point out the non-negligible influence of perforations, depending on the specimen lengths (i.e. on the failure modes): differences ranges from $10 \%$ up to $30 \%$.

As to the flexural behaviour, three different type of tests have been carried out in order to capture the profile response along the principal axes of the cross-section, one of which is also a symmetry axis. Resistance is strongly influenced by strain hardening effects due to the cold working processes, with non-negligible benefits for both sets of specimens: up to $34 \%$ with respect to the elastic bending moment of solid profiles and quite moderately reduced for perforated members. Furthermore, bending tests data have been analysed focussing attention on the experimental evaluation of the effective second moments of area $\left(I_{e f f, k}\right)$. Owing to lack of indications in standard codes, three different procedures have been developed and applied. Results show that independently of the considered procedure:

- the value of $I_{e f f, k}$ depends in a non-negligible way on the range of the data considered for the analysis;

- in case of bending about the non-symmetric axis, two different values of the second moment of area characterize the flexural response, depending on the parts of the cross-section in tension/compression;

- the three different procedures applied to assess $I_{\text {eff,k }}$ lead to quite different results;

- the influence of perforations on both resistance and stiffness is non-negligible, despite a very limited portion of the module interested by the slots (Figure 4);

- the equivalent solid cross-section according to [35] cannot be used to assess the effective area, leading to non-negligible overestimation. Furthermore, this approach allows for an estimation of the flexural behaviour acceptable for design purposes.

Finally, it is worth noting that improvements related to the experimental evaluation of the second moments of area are urgently required in rack provisions, affecting these quantities the set of internal forces on which routine design is based. In addition to the detailed layout to be adopted for the end restraints of the uprights in bending, also the mandatory assessment of the elastic modulus should be imposed by the rack design codes. The non-negligible differences from the nominal value associated with the material test results of the present research, confirmed also by [44] could affect significantly the actual degree of safety of the storage rack systems, owing to the influence of the material modulus on both ultimate and serviceability limit state checks.

\section{Acknowledgments}

Authors would like to express their personal thanks to Mr. Antonello Briosi, Mr. Mirco Briosi and Dr. Lucio Gelmini of 'Metalsistem S.p.A.' where the experimental phase of this study has been carried out. 


\section{References}

[1] Rhodes J., "Introduction to cold formed steel sections, Chapter 1", in Design of cold formed steel members, Edited by Rhodes J., Elsevier Science Publishers LTD, Crown House, Essex, England, ISBN pp. 1-50, 1991.

[2] Dubina D., Ungureanu V., Landolfo R., "Design of cold-formed steel structures, Eurocode 3: design of steel structures, Part 1-3 - design of cold-formed steel structures", 1st edition, Wiley-Blackwell, Hoboken, NJ, pp. 654, 2012.

[3] Hancock G.J., "Design of cold-formed structures (to AS/NZS 4600:2005)", 4 ${ }^{\text {th }}$ edition, Australian Institute of Steel Construction, pp. 248, 2007.

[4] Loughlan J., Nash D.H., Rhodes J., Coupled Instabilities in metal structures, Thin-Walled Structures, 81, pp. 1-17, 2014.

[5] Schafer B.W., Local, distortional and Euler buckling in thin-walled columns, Journal of Structural Engineering (ASCE), 128(3), pp. 89-99, 2002.

[6] Martins A.D., Camotim D., Dinis P.B., Young B., Local-distortional interaction in coldformed steel columns: mechanics, testing, numerical Simulation and design, Structures 4, pp. 38-57, 2015.

[7] Dubina D., Ungureanu V., Instability mode interaction: from Van Der Neut model to ECBL approach, Thin-Walled Structures, 81, pp. 39-49, 2014.

[8] CEN, "Eurocode 3 - Design of Steel Structures - Part 1-3: Design of cold formed members", European Committee for Standardization, Brussels, pp. 130, 2005.

[9] Winter G., Performance of compression plates as part of structural members, Research, Engineering Structures Supplement, Colston Paper, vol. II, Butlerwont, London, pp. 179$184,1949$.

[10] AISI S100-16, "North American specification for the design of cold-formed steel structural members", American Iron and Steel Institute, Washington, pp. 136, 2016.

[11] Schafer B.W., Pekoz T., Direct strength prediction of cold-formed steel members using numerical elastic buckling solutions. Thin-Walled Structures, Research and Development. Proceedings of the $2^{\text {nd }}$ International Conf. on Thin Walled Structures, Singapore, Elsevier, pp.137-44, Dec. 1998.

[12] Schafer B.W., The direct strength method of cold-formed steel members, Journal of Constructional Steel Research, 64 (7-8), pp. 766-778, 2008.

[13] VijayaVengadesh K. J., Arul Jayachandran S., Experimental investigation and evaluation of Direct Strength Method on beam-column behaviour of uprights, Thin- Walled Structures, 102, pp. 165-179, 2016.

[14] Moen C.D., Schafer B.W., Elastic buckling of thin plates with holes in compression or bending, Thin-Walled Structures, 47, pp. 1597-1607, 2009.

[15] Smith F.H., Moen C.D., Finite strip elastic buckling solutions for thin-walled metal columns with perforation patterns, Thin-Walled Structures, 79, pp. 187-201, 2014

[16] Moen C.D., Schafer B.W., Experiments on cold-formed steel columns with holes, ThinWalled Structures, 46, pp. 1164-1182, 2008.

[17] Baldassino N., Hancock G.J., Distortional buckling of cold-formed steel storage rack sections including perforations. Proceedings of the $4^{\text {th }}$ International Conf. on Steel and Aluminium Structures (ICSAS'99), Helsinki, Oxford Elsevier, pp. 131-138, June 1999.

[18] Casafont M., Pastor M.M., Roure F., Bonada J., Pekoz T., An investigation on the design of steel storage rack column via the direct strength method, Journal of Constructional Steel Research, 139(5), pp. 669-679, 2013.

[19] Moen C.D., "Direct strength design for cold-formed steel members with perforations", $\mathrm{PhD}$ Thesis, Johns Hopkins University, Baltimore, 2008.

[20] VijayaVengadesh Kumar J., "Buckling behaviour of cold-formed steel rack uprights", $\mathrm{PhD}$ thesis, Indian Institute of Technology Madras, pp. 207, 2016. 
[21] Zhao X., Ren C., Qin R., An experimental investigation into perforated and non-perforated steel storage rack uprights, Thin-Walled Structures, 112, pp. 159-172, 2017.

[22] Baldassino N., Zandonini R., Design by testing of industrial racks, Advanced steel construction, 7 (1), pp. 27-47, 2011.

[23] Bertocci L., Comparini D., (...), Spinelli P., Experimental, numerical and regulatory $\mathrm{P}_{\mathrm{x}}-\mathrm{M}_{\mathrm{x}^{-}}$ $\mathrm{M}_{\mathrm{y}}$ domains for cold-formed perforated steel uprights of pallet racks, Thin-Walled Structures, 119, pp. 151-165, 2017.

[24] Zhang P., Sharia A. M., Experimental investigation and numerical simulation of pallet-rack stub columns under compression load, Journal of Constructional Steel Research, 133, pp. 282-299, 2017.

[25] Crisan A., Ungureanu V., Dubina D., Behaviour of cold-formed steel perforated sections in compression: Part 2- numerical investigations and design considerations, Thin-Walled Structures, 61, pp. 97- 105, 2012.

[26] Roure F., Pastor M.M., Casafont M., Somalo M.R., Stub column tests for racking design: Experimental testing, FE analysis and EC3, Thin-Walled Structures, 49, 167-184, 2011.

[27] Shah S.N.R., Sulong N.H.R., Jumaat M.Z., Shariati M., State-of-the-art review on the design and performance of steel pallet rack connections, Engineering Failure Analysis, 66, pp. 240258, 2016.

[28] Petrone F., Higgins P.S., Bissonnette N.P., Kanvinde A.M., The cross-aisle seismic performance of storage rack connections, Journal of Constructional Steel Research, 122, pp. 520-531, 2016.

[29] Sangle K.K., Bajora K.M., Talicotti, R.S., Stability and dynamic analysis of cold-formed storage rack structures with semirigid connections, International Journal of structural stability and dynamics, 11 (6), pp. 1059-1088, 2011.

[30] Sena Cardoso F., Rasmussen K.J.R., Finite element (FE) modelling of storage rack frames, Journal of Constructional Steel Research, 126, pp. 1-14, 2016.

[31] The L.H., Hancock G.J., Clarke M.J., Analysis and design of double sided high-rise steel pallet rack frames, Journal of Structural Engineering, 130, pp. 1011-1021, 2004.

[32] Gabbianelli G., Kanyilmaz A., Bernuzzi C., Castiglioni C.A., A combined experimentalnumerical study on unbraced pallet rack under pushover loads, Ingegneria sismica, 34 (1), pp. 18-38, 2017.

[33] Bernuzzi C., Di Gioia A., Gabbianelli G., Simoncelli M., Pushover analyses of hand-loaded steel storage shelving racks, Journal of Earthquake Engineering, 21 (8), pp. 1256-1282, 2017.

[34] CEN, "EN 15512, Steel static storage systems - Adjustable pallet racking systems Principles for structural design", European Committee for Standardization, pp. 138, 2009.

[35] CEN, prEN “15512, Steel static storage systems - Adjustable pallet racking systems Principles for structural design”, European Committee for Standardization, pp. 288, 2017.

[36] Baldassino N., Bernuzzi C., Simoncelli M., On the reliability of the approaches for static design of steel storage pallet racks, in preparation.

[37] Baldassino N., Bernuzzi C., Simoncelli M., An experimental-numerical analysis on steel storage racks under increasing gravity loads till collapse, in preparation.

[38] Moen C.D., Igusa T., Schafer B.W., Prediction of residual stresses and strains in cold-formed steel members, Thin-Walled Structures ,46 (11), pp. 1274-1289, 2008.

[39] Crisan A., Ungureanu V., Dubina D., Behaviour of cold-formed steel perforated sections in compression: Part 1-Experimental investigations, Thin-Walled Structures, 61, pp. 86-96, 2012.

[40] ISO EN 6892-1:2016, "Metallic materials - tensile testing- Part1: method of test at room temperature", 2016.

[41] Schafer B.W., "CUFSM: Elastic buckling analysis of thin-walled members by the finite strip method". (Open Source Software) www.ce.jhu.edu/bschafer/cufsm, 2005. 
[42] Elias G.C., de Almeida Neiva L.H., Sarmanho A.M.C., Alves V.N., Barbosa e Castro A.F., Ultimate load of steel storage systems uprights, Engineering Structures, 170, pp. 53-62, 2018.

[43] Saleh A., Far H., Mok L., Effects of different support conditions on experimental bending strength of thin walled cold formed steel storage upright frames, Journal of Constructional Steel Research, 150, pp. 1-6, 2018.

[44] Sadowski A. J., Rotter M. J., Reinke T., Statistical analysis of the material properties of selected structural carbon steels, Structural safety, 53C, pp. 26-35, 2014. 